\title{
MODELO PARA ANÁLISE DAS VARIÁVEIS DE COBERTURA DA TERRA E A IDENTIFICAÇÃO DE MICROCLIMAS, EM CENTROS URBANOS
}

\author{
FERREIRA, Cássia de Castro Martins - cassia.castro@ufjf.edu.br \\ Dep Geografia - Univ. Federal de Juiz de Fora/MG
}

\begin{abstract}
RESUMO: Pesquisadores brasileiros e estrangeiros afirmam que as atividades, fluxos e equipamentos presentes nas cidades influenciam/modificam o clima regional e consequentemente criam um clima urbano. Esta relação atmosfera/cidade ocorre por que as variáveis climáticas são alteradas em função da modificação do balanço de energia e fluxos de ar. Para isso, propõe-se uma metodologia baseada em mapeamentos básicos e temáticos com alto detalhamento, associados a análises qualitativas, o mapeamento é constituído a partir de layers onde as informações geográficas relacionadas tanto a produção (albedo, emissividade, massa construída, poluição do ar, fator visão do céu, taxa de impermeabilização) quanto à mitigação (áreas verdes, água, ventilação, sombreamento) de campos térmicos, são associados a uma matriz de pesos determinada pela influência de cada variável na temperatura local. O modelo, quando comparado com registros de temperatura do ar em superfície, evidenciou uma alta correlação, sendo possível ser utilizado no planejamento e gestão urbanos, visando o alcance de melhor conforto térmico e consequente qualidade de vida.
\end{abstract}

Palavras-Chave: mapeamento temático, clima urbano, modelo climático.

MODEL FOR ANALYSIS OF MAIN DECK THE EARTH AND IDENTIFICATION OF MICROCLIMATES IN URBAN CENTERS

ABSTRACT: Brazilian and foreign researchers claim that the activities, streams and equipment in the cities influencing / modifying the regional climate and consequently creating an urban atmosphere. This relationship atmosphere / city occurs why climatic variables are changed due to the modification of energy balance and air flows. For this, we propose an approach based on basic and thematic maps with very detailed methodology, associated with qualitative analyzes, the mapping is made from layers where geographical information related both production (albedo, emissivity, built mass, air pollution, the sky view factor, rate of waterproofing) and mitigation (green areas, water, ventilation, shading) of thermal fields, are associated with an array of weights determined by the influence of each variable on the local temperature. The model, when compared with records of surface air temperature, showed a high correlation, which can be used in urban planning and management, aimed at achieving better thermal comfort and resulting quality of life.

Keywords: Thematic mapping, urban climate, climate model

\section{INTRODUÇÃO}

A produção do espaço pela sociedade leva à concentração dos sistemas de objetos e de ações indispensáveis à sua manutenção, principalmente nas cidades, ambiente que apoia o desenvolvimento dos processos reais e naturais, além dos processos virtuais e artificiais. Implicando em ambientes urbanos cada vez mais dependentes de tecnologias modernas, infraestruturas complexas e de energia para dinamizar todos esses processos. Logo, cidades desenvolvidas se caracterizam por serem as que mais atraem fluxos, o que torna este espaço cada vez mais vulnerável a qualquer falha no sistema, sendo cada vez mais artificial, com alto risco e baixa resiliência.

Desta forma, cada vez mais são produzidos espaços urbanos altamente insustentáveis, consagrando uma veemente ruptura socioambiental. Que pode ser detectado com a alteração na forma e distribuição da população no mundo, que hoje se concentra em áreas urbanas. A este fato se soma o tipo de organização e ocupação da terra, que passou a ocupar menor área per capita, o ritmo e o tipo de consumo de recursos naturais, que foi influenciado pelo estilo de vida e padrão de bem estar urbano, que gerou um aumento da sua pegada ecológica.

Logo, Monteiro (2010, p. 8) afirma que "o balanço entre a capacidade ecológica do território e a pegada ecológica gerada por este novo modelo de ocupação do espaço passou a ser, na maioria dos países, muito deficitário." Destaca ainda que no Brasil, em 2007, o déficit 
ecológico é de $-0,1$ há/per capita, no globo a média é de -0,5/ per capita (MONTEIRO, 2010, p. 8-9).

Este crescente processo de artificialização e consequente desequilíbrio entre a oferta de recursos naturais e o consumo destes pela população urbana, pode ser minimizado, quando ocorre um maior conhecimento e detalhamento das formas e estruturas pelo qual a cidade esta assentada. Um dos elementos que hoje toma uma maior relevância, principalmente no contexto urbano são as condições de tempo e as implicações no sítio urbano, que são percebidas e difundidas, seja no contexto de um futuro aquecimento global, ou nas repercussões diárias e vividas pela população, como enchentes urbanas, calor extremo, seca, movimentos de massa, entre outros. Eventos que interferem no cotidiano do citadino e causa interferências nas relações ecossistêmicas. Além disso, estes eventos estão frequentemente associados a prejuízos e perdas materiais e de vidas humanas, além de contribuir para a potencialização de processos naturais, que sem a intervenção humana levariam períodos extensos para se desenvolverem.

O clima, portanto deixa de ser um elemento estanque e passa a ser uma variável importante na definição de padrões, decisões, localização, atividades, pois age, impacta, influencia, potencializa, dinamiza as relações e processos relacionados ao suporte biogeofísico natural.

Como então explicar e entender como é possível verificar diferentes microclimas intraurbanos, ao mesmo tempo e sob as mesmas condições meteorológicas e climáticas?

Como entender a dimensão social da variabilidade climática e os microclimas?

Como considerar os processos sociais na explicação das diferenças na repercussão de um mesmo evento climático entre os bairros de uma mesma cidade?

Tentando encontrar respostas e caminhos para estas questões, procuramos destacar a função da análise espacial, que permite a compreensão dos fenômenos de localização, distribuição e distinção do clima urbano e eventos associados, tais como inversão térmica, ilhas de calor, campos térmicos, etc. E na compreensão do papel dos elementos que contribuem para que o clima urbano aconteça.

Com a progressiva adoção de abordagens sistêmicas na análise climática, dando um caráter mais complexo e dinâmico, os estudos passam a buscar a gênese dos mecanismos que desencadeiam a formação de um clima urbano, ampliando o alcance dessa análise. $\mathrm{E}$, na perspectiva crítica, a análise da relação entre o clima e a sociedade, considera as diferenças nas formas de receber a variabilidade climática pelas distintas classes sociais ou das pessoas nos diferentes contextos socioespaciais.

Porém, como chegarmos a uma análise crítica desta relação clima-cidade, sem antes termos um inventário minucioso dos elementos que compõem o espaço urbano, tais como os revestimentos, altura e cor das edificações e como estes se comportam sob a recepção direta ou difusa da radiação solar, impermeabilização, densidade de construções, áreas verdes, espaços livres, topografia, etc, enfim, qual a interferência de todos estes aspectos numa análise espacial conjunta, sistêmica.

Como elaborar um modelo de análise que permita considerar o conjunto e as relações das variáveis numa dimensão espaço-temporal e hierárquico, em uma escala de detalhe, permitindo verificar e entender a distribuição espacial de microclimas e os principais elementos intervenientes?

Partindo desta meta, optou-se pelo uso das geotecnologias, pois estas permitem integrar a análise espacial. Com a estatística espacial, além da modelagem de um grande conjunto de dados e da visão de conjunto do ambiente, no qual, podem ser levantadas simultaneamente as características físicas (clima, relevo, geologia, etc), bióticas (vegetação, fauna) e socioeconômicas (renda, população, etc). 
Logo, o uso de métodos geoestatísticos, acoplados a um Sistema de Informações Geográficas, permitem a caracterização de fenômenos espaciais e a quantificação do seu conhecimento, permitindo ainda, generalizar o comportamento de uma variável, para áreas aonde os dados são inexistentes.

Como a maior parte dos dados climáticos disponíveis são pontuais, esta ferramenta possibilitaria estimar para as áreas com ausência do dado real, com maior acerto. Ou mesmo, precisar quais elementos presentes na superfície urbana mais influenciariam nas diferenças térmicas entre uma localidade e outra e não apenas a enumeração de todos as variáveis como se elas tivesses o mesmo peso, comportamento e influência na temperatura do ar.

Os sistemas de informações geográficas se caracterizam por um conjunto de ferramentas que permite a captura, o armazenamento, a atualização e a exibição de dados, além de proporcionar análises e integrações de dados ambientais (BURROUGH, 1986; XAVIER-DASILVA et al., 2001; ARANOFF, 1989). Estas técnicas permitem e subsidiam as análises espaciais de elevados conjuntos de dados, possibilitando integrar informações espacialmente referenciadas, viabilizando criar projeções e detectar comportamentos espaciais, podendo ainda relacionar com outros dados territoriais.

A aplicação do Sistema de Informações geográficas e da estatística espacial permitiu modelar geograficamente diferentes fenômenos, aqui tratados principalmente aqueles atrelados ao comportamento térmico urbano da região central da cidade de Juiz de Fora-MG. Permitindo definir padrões térmicos diferenciados no espaço, mas principalmente pela alta definição e caracterização dos elementos que compõem e revestem a superfície, permitindo analisar os principais elementos causadores de campos térmicos na área urbana.

\section{2-MEDIÇÃO E SIMULAÇÃO DE CAMPOS TÉRMICOS}

Porque a temperatura das cidades é diferente?

Esta é uma pergunta que muitos pesquisadores vêm respondendo, desde quando ocorreram as primeiras constatações de que havia uma diferença de temperatura entre o rural e a área urbana de Londres, em 1833, por Howard.

Posteriormente, o número de pesquisas baseadas em diferentes teorias e principalmente metodologias e técnicas foram utilizadas afim de, representar, mapear, descrever e explicar a configuração do clima urbano, além de suas causas e efeitos.

Durante este tempo, várias abordagens foram empregadas e são mais comumente utilizadas para investigar, medir e simular o estudo do clima urbano. Separamos em quatro eixos principais de investigação, aquelas atreladas à análise de séries temporais climatológicas, normalmente apoiadas no emprego de análises estatísticas (GANHO, 1992; BRANDÃO, 1987 e 1992; CABRAL, 1996; CHANGNON, 1999; TURKES et al., 2002; VENTURA et al., 2002; CHUNG et al., 2004; XAVIER e PEREIRA FILHO, 2007; HOMAR et al., 2010). As que utilizam na investigação transectos de redes móveis, objetivando aumentar os pontos de observação e verificar espacialmente as variações das temperaturas intra-urbanas (HAGE, 1972; CARRERAS et al., 1990; GARCIA, 1991; MAITELLI, 1994; MONTEIRO, 1997; MELHUISH, PEDDER, 1998; FIALHO, 2002; AMORIM, 2005; VIANA, 2006; BRANDÃO, 2009; MAITELLI, et al., 2003; SUN et al., 2009; MURPHY et al., 2011).

Há ainda os que trabalham com os dados existentes em uma rede de monitoramento de postos fixas, localizadas na área urbana. São utilizados mini-abrigos meteorológicos, estações automáticas e/ou as estações oficiais vinculadas a ANA, ANEEL e INMET (TARIFA, 1977; LOMBARDO, 1985; DANNI, 1980; MENDONÇA, 2001; ASSIS, 2001; HINKEL et al., 2003; PEZZUTO et al., 2005; COSTA e LABAKI, 2006; BAI e MIKAMI, 2006; HEISLER et al., 2006; DREBS VODJA E TUOMENVISTA, 2006; ANDREOTI, 2009;). 
E o uso do sensoriamento remoto, que viabiliza uma análise areal, além de maior discretização dos dados. O sensoriamento remoto em vários estudos tem sido utilizado concomitantemente ao uso dos transectos móveis ou fixos, normalmente para validar os resultados encontrados na interpretação de imagens de satélite (STATHOPOULOU e CARTALIS, 2009; STREUTKER, 2003; SOLECKI et al., 2005; PAULEIT et al., 2005; CHEVAL e DUMITRESCU, 2008; POLIZEL, 2009; IMHOFF et al., 2010).

Além destas abordagens, são ainda empregados modelos que permitem simular a atmosfera urbana, ressaltamos principalmente dois tipos, os modelos de balanço de energia, que visam a modelagem do clima urbano a partir dos fluxos de calor no sistema terra-atmosfera. Em sua maioria trabalham com o pressuposto de que o equilíbrio Global é alterado na escala local urbana em função da exposição à radiação solar e pelas características da atmosfera, do solo e das superfícies (OKE, 1976; YOSHIKADO, 1994; EZBER et al., 2007; VAN WEVERBERG et al., 2007; MOCHIDA et al., 2007; KARAM et al., 2010; ZHANG et al., 2010; BORNSTEIN et al., 2012). E os modelos numéricos que são utilizados para análise da atmosfera urbana, geralmente destinados a uma mesoescala, e se destinam a uma análise espacial e temporal (OKE, 1976; GRIMMOND e OKE, 1991; MASSON, 2000; KUSAKA et al., 2001; WEBER e PUISSANT, 2003; LEMONSU et al., 2004; KANDA, 2006; LIN et al., 2010).

Destaca-se ainda que vários destes autores fazem seus estudos mesclando mais de uma abordagem, afim de garantir tanto a veracidade da informação/dado, quanto uma maior aproximação da realidade.

\section{3- O CLIMA URBANO E MODELOS ESPACIAIS}

Pesquisadores brasileiros e estrangeiros afirmam que as atividades, fluxos e equipamentos presentes nas cidades influenciam/modificam o clima regional e consequentemente criam um clima urbano. Esta relação atmosfera/cidade ocorre por que as variáveis climáticas são alteradas em função da modificação do balanço de energia e fluxos de ar.

Esta situação afeta o conforto térmico, qualidade de vida, saúde da população e a demanda de energia nas áreas urbanas. Porém, os efeitos climáticos não são considerados adequadamente no planejamento e gestão urbanos, verificado pela priorização nas últimas décadas das questões econômicas de curto prazo e na rápida urbanização.

O efeito da cidade no clima urbano seja na "camada limite de dossel" que se caracteriza pela área entre o solo e o nível da cobertura das edificações, no qual se encontram os processos de microescala, presentes nas ruas, prédios, entre prédios (OKE, 2004; 2006; Grimmond, 2006), ou na "camada limite urbana", que estende-se acima do nível dos telhados, com características produzidas pela natureza da superfície urbana, é influenciada pela estrutura urbana, pelas edificações (altura, distância entre elas), pelas vias (fluxos de veículos, largura), que por sua vez influenciam na rugosidade, ocasionando uma aerodinâmica particular, pois a velocidade do vento diminui, provoca um aumento da turbulência e no arrasto provocado pela fricção do ar (OKE, 2004; 2006; Grimmond, 2006).

Os "canyons urbanos" são formados pelos corredores presentes entre as paredes de altas edificações, sendo um exemplo de situações que ocorrem na "camada limite de dossel". No interior dos "canyons urbanos", a radiação é refletida várias vezes entre as paredes das edificações e ruas presentes neste espaço, provocando diferentes absorções, minimizando processos de convecção e diminuindo a velocidade dos ventos.

Outros processos como albedo, emissividade e capacidade térmica, são influenciados pela altura, largura, comprimento, cor, superfícies lisas, foscas, brilhantes dos materiais utilizados na construção do espaço urbano.

Quando a velocidade dos ventos é reduzida, pela presença da rugosidade, aumenta o armazenamento de calor durante o dia e em função das características dos materiais, corre 
uma lenta liberação deste calor ao longo da noite, sendo este um dos fatores responsáveis pela formação de ilhas de calor noturnas (OKE, 1981; GRIMMOND, 2006; GARTLAND, 2010).

As cidades apresentam no seu interior uma variedade muito grande de tipos de superfícies, com diferentes revestimentos e capacidades de armazenar e refletir calor, estas superfícies estão ainda distribuídas ao longo do tecido urbano de forma concentrada, geralmente nas áreas centrais, com alta verticalização e fluxos de veículos e pessoas, desconcentradas, contínua, descontínua, etc) e o metabolismo urbano (presença de água, poluentes, calor antropogênico), todos estes processos vão interferir na atmosfera urbana, a grande questão seria identificar o quanto eles influenciam isoladamente, hierarquicamente e em conjunto.

Grimmong (2006) destaca que os processos atmosféricos ocorrem em diferentes escalas espaciais urbanas, que vão desde a camada limite planetária, passando pela camada limite urbana e finalizando na camada limite de dossel, respondendo respectivamente as escalas regional, local e micro.

Quanto mais a escala de detalhe aumenta, mais complexa e melhores são as possibilidades de entender e avaliar os elementos e variáveis definidoras dos diferentes microclimas presentes nas cidades.

Esta intensa interferência reflete no conforto humano, na saúde ambiental da cidade, na eficiência energética, no ambiente físico e na qualidade de vida (NG et al., 2008; KATZCHNER et al., 1999; REN et al., 2010; ACERO et al., 2012). Todos estes aspectos são apontados nos parâmetros de cidades sustentáveis, preconizado pela ONU em 2008. Porém as informações climáticas na escala urbana possuem pouco ou nenhum impacto nas tomadas de decisões no planejamento urbano/ambiental das cidades, mesmo diante do crescente número de episódios de enchentes, movimentos de massa, ondas de calor e frio, verificados em várias cidades brasileiras. Decorrentes em sua maioria da rápida urbanização, na maior parte das vezes sem nenhum planejamento e na priorização das questões econômicas de curto prazo e não tratando as questões ambientais de forma adequada.

Desta forma, o clima urbano precisa ser considerado e consolidado como uma variável importante para o planejamento urbano, principalmente no contexto de possíveis mudanças climáticas, que poderiam repercutir em um aumento da temperatura do ar, precipitações mais concentradas, secas prolongadas, etc., o que poderia influenciar na dinâmica das cidades, no aumento do calor e consequente desconforto térmico, no aumento das enchentes urbanas e movimentos de massa, em função da maior concentração da precipitação e alteração dos espaços urbanos (impermeabilização do solo, retirada da cobertura vegetal, etc.). Todas estas situações, já são vivenciadas e vem repercutindo em sucessivas perdas materiais e de vidas humanas pela população urbana na atualidade. O que seria, portanto, se tivéssemos um aumento no número destes episódios?

Como tornar os dados climáticos acessíveis e válidos ao planejamento urbano, pois os planos diretores, de um modo geral reservam uma pequena parte do seu volume de diagnóstico para colocar uma descrição do clima da cidade, normalmente baseada em uma classificação climática ou utilizando dados médios de temperatura do ar e precipitação. Sem nenhuma relação imediata com o clima urbano e as diferentes formas que este poderia ser utilizado no planejamento da cidade. Seja na dimensão futura ou atual, a questão climática e o ordenamento do território deveriam ser analisados conjuntamente, pois auxiliaria nas tomadas de decisões e minimizaria a vulnerabilidade e os riscos, que na maior parte das cidades brasileiras ao invés de diminuírem vem aumentando significativamente (EM-DAT, The International Disaster Database, CRED, 2014).

Em 2012, 100\% dos desastres naturais que ocorreram no Brasil, são classificados em hidro meteorológicos, envolvendo secas, ondas de calor e frio, queimadas, ventos, incêndios florestais, temperaturas extremas, movimentos de massa, enchentes, inundações e tempestades (EM-DAT, The International Disaster Database, CRED, 2014). 
Mas como minimizar, ou mesmo eliminar o risco? E a vulnerabilidade das pessoas? Monteiro (2013, p.145) destaca que a competência no controle da vulnerabilidade das pessoas e bens materiais, está atrelado ao maior conhecimento dos processos envolvidos no fenômeno causador da ameaça, e na identificação dos elementos promotores da vulnerabilidade.

Logo, "o que confere gravidade ao risco num sistema caótico que é intrinsecamente variável, não pode ser a excepcionalidade do comportamento do sistema climático mas, sim, o grau de vulnerabilidade da sociedade onde acontece. $\mathrm{E}$, é aqui que verdadeiramente interessa centrar a nossa atenção geográfica sobre o comportamento do sistema climático, neste período interglacial que decorre, numa época de grande convicção nas potencialidades da ciência e da técnica" (MONTEIRO, 2013, p. 146).

Desta forma, o clima urbano requer um conhecimento geográfico da cidade, apoiado em técnicas cartográficas que permita a espacialização e classificação da cidade em unidades homogêneas (MENDONÇA, 2003).

Como as cidades brasileiras possuem uma grande heterogeneidade de espaços, com diferentes padrões de edificações, marcados pelos materiais de construção, coloração, densidade, áreas verdes, espaços livres, vias, etc. Essas diferenças "não podem ser ignoradas na análise do clima das nossas cidades", como bem destaca Monteiro (1990, p.67).

Logo, as ações humanas dão as cidades suas particularidades e o estudo do clima urbano, não pode negligenciar estas diferenças, e para identificá-las ressaltaremos algumas pesquisas que tiveram como objetivo central identificar, mapear e classificar a cidade levando em consideração a relação entre o espaço geográfico urbano e o clima.

Steward e Oke (2009) aponta o trabalho desenvolvido por Aver, que propôs uma classificação climática para a cidade, utilizando as variáveis atreladas ao uso da terra e da cobertura vegetal.

Oke (2006) destaca a classificação realizada por Ellefsen (1990) que elaborou um modelo, baseado na morfologia da construção, configuração das vias e nos materiais de construção e a relação destes com o clima urbano. Em um segundo momento da pesquisa Ellefsen, acrescenta a análise a rugosidade, a altura e a densidade das edificações.

Em 2006, Oke (2006) propõe um sistema de classificação climática, discriminando padrões urbanos, organizados em ordem da sua capacidade de alterar o clima local. Dentre as variáveis utilizadas estão a rugosidade, tipo de cobertura, impermeabilização e tipos de uso da terra. A relação entre estas variáveis possibilitou identificar zonas climáticas urbanas, baseadas na delimitação de áreas homogêneas.

Estabelecendo uma análise mais abrangente e integrada, em 2009, Steward e Oke (2009) estabeleceu uma classificação que teve como base a análise da paisagem, no qual, transitam entre uma análise mais global, até chegar a unidades menores. As unidades menores foram delimitadas em função das propriedades urbanas, no qual foram consideradas as variáveis: altura da rugosidade superficial, fração da superfície impermeável, fator de visão do céu, desempenho térmico, albedo e fluxo de calor antropogênico. Esta classificação permitiu um maior controle metodológico, o que possibilita a aplicação deste modelo classificatório em outras cidades.

O estudo realizado por Collischonn e Mattos (2011) para a cidade de Pelotas-RS, é um exemplo de aplicação do modelo proposto por Steward e Oke (2009), visando identificar as potenciais unidades climáticas para a cidade, para obter as variáveis foi utilizado imagens de satélite de alta resolução espacial. Resultando na definição de 19 potenciais unidades climáticas para o perímetro urbano de Pelotas-RS.

Com a mesma concepção de integrar e relacionar dados climáticos, com uso da terra e informações sobre a superfície, surge o conceito de "Climatic Urban Map" (UC-MAP), visava criar uma base de dados que possibilitava o conhecimento do clima urbano e os fatores 
geográficos intervenientes, com a finalidade de apoiar o planejamento urbano Knoch (1951, 1963) propôs um sistema de mapeamento climático, denominado (UC-Map). Este sistema consistia basicamente em criar mapas básicos climáticos e de uso da terra, que possibilitariam uma análise integrada e conjunta além da identificação de áreas com o conforto térmico. Estes dados dariam posteriormente, subsídios ao planejamento urbano. Um dos principais objetivos deste projeto era o mapeamento das informações, o que possibilitava obter uma análise espacial dos parâmetros utilizados.

Normalmente os sistemas UC-Map consistem em gerar duas respostas principais, um mapa climático urbano e um mapa de recomendação climática urbana. Estes mapas são gerados a partir de variáveis meteorológicas, uso da terra, topografia e vegetação. Teve seu desenvolvimento atrelado à necessidade de fornecer recomendações estratégicas para o planejamento urbano. Várias cidades europeias passaram a criar seus UC-Map, seja de forma adaptada às condições específicas do seu sítio urbano e climáticos, ou na versão original (REN e KATZSCHNER, 2007; REN et al., 2010) se estendendo em vários países como Suécia (SVENSSON et al., 2003), Israel (ERELL et al., 2003), China (WANG, 2004), Polônia (USTRNUL e CZEKIERDA, 2005), Brasil (NERY et al., 2006), Alemanha (KATZSCHNER e MÜLDER, 2008), Japão (TANAKA et al., 2009), Portugal ALCOFORADO et al., 2009), entre outros. No Brasil a metodologia chegou a ser empregada, porém foram encontrados muitos obstáculos em adaptá-la, em função da alta heterogeneidade do sítio natural e da estrutura urbana.

A seguir alguns exemplos de uso e adaptação desta metodologia para algumas cidades no mundo. Com o aumento da poluição do ar em áreas urbanas, foram utilizados mapas climáticos e de uso da terra para alcançar uma análise integrada e mitigar os problemas advindos da poluição do ar, possibilitando o uso deste estudo no planejamento ambiental e no ordenamento do território (BAUMÜLLER e REUTER, 1999; BAUMÜLLER, 2006).

Aplicando o UC-AnMap foram relacionados os fatores climáticos urbanos com a informação espacial e a estrutura urbana e com base nos dados de uso do solo e do clima, definindo classes, que indicam áreas com diferentes condições climáticas. Esta metodologia foi utilizada para controlar a poluição por metais pesados nas antigas áreas industriais de Ruhr (REN et al., 2010).

$\mathrm{Ng}$ et al. (2008) criou um modelo de mapeamento climático, utilizando o geoprocessamento para a execução e criação de mapas climáticos e de elementos urbanos. A cada variável utilizada são dados pesos (em função do grau de importância da variável, no conforto térmico), da integração entre estas variáveis é criado um mapa de classificação das áreas termicamente mais ou menos confortáveis. No modelo aplicado para a cidade de Hong Kong, foram utilizadas as variáveis uso e ocupação do solo, cobertura do solo, áreas construídas, volume construído e topografia. Foi dividido em duas partes principais, uma referente ao critério físico e outro com dados de entrada baseados no critério físico. O primeiro critério físico mostra o grupo de fatores responsáveis pelo aumento da temperatura. O segundo e terceiro critérios físico, são apresentados os fatores que poderiam reduzir a temperatura. As informações são sobrepostas e são alocados pesos para cada uma das variáveis, resultando em dois mapas principais, um mapa de diagnóstico, que apresenta as diferentes condições climáticas da cidade e o segundo, com possibilidades de planejamento, visando atenuar a ilha de calor.

Uma sequência de ondas de calor entre 2003 e 2006, levou vários países europeus a darem mais atenção ao clima urbano e às alterações no ordenamento do território, o que levou vários países a aplicarem a metodologia desenvolvida na Alemanha, baseada no modelo UC-Map. $\mathrm{Na}$ França, um estudo multi-disciplinar sobre os impactos das alterações climáticas, chamado projeto EPICEA, iniciado em 2008, foi implantado objetivando conhecer e entender a onda de calor que ocorreu no verão de 2003 em Paris (DESPLAT et al., 2009). Foram utilizados dados de mortalidade e parâmetros ambientais, além de dados atrelados às edificações, como material utilizado nos telhados.

Acero et al. (2012) aplicou uma metodologia em Bilbao-Espanha, baseada no Urban Climate Map (UCMap) que é considerado uma ferramenta de informação sobre o clima, numa 
perspectiva do planejamento urbano. Baseia-se na combinação de camadas de informação geográfica que incluem variáveis climáticas (temperatura e vento) e dados geográficos (uso do solo, propriedades de ventilação da área urbana e áreas verdes). Visando avaliar e classificar o conforto térmico na área urbana.

Outro exemplo de aplicação, foi apresentado pelo estudo de Ren et al. (2010), que apresentou uma ferramenta chamada de Urban Climate Map System (UCMS), este foi desenvolvido e apresentado em uma plataforma SIG, que compatibiliza dados qualitativos e quantitativos. Objetivando criar sinergias à compreensão e análise do fator climático (vento, temperatura, umidade, vento, chuva, fog, poluição do ar), analisando conjuntamente ao uso da terra e informações mais detalhadas sobre as edificações, além dos dados de topografia, declividade, vale e solos. O sistema viabiliza a produção de um mapa climático que tem por finalidade auxiliar no planejamento urbano, para isso foi aplicado em Arnhem-Holanda.

\section{4- HIPÓTESE}

A cidade com o tempo vem passando por um processo rápido de adensamento e verticalização, modificando sua geometria urbana. As variáveis que mostram a alteração do ambiente urbano, aqui consideradas: massa construída, fator de visão do céu, taxa de impermeabilização, poluição do ar, albedo, emissividade dos materiais, áreas verdes e livres, água, etc. podem influenciar a temperatura do ar?

1- Qual o peso e grau de influência de cada destas variáveis?

2- Pode-se chegar e mapear os campos térmicos urbanos, por meio da identificação do comportamento destas variáveis?

3- É possível estabelecer um modelo, baseado nestas variáveis, para monitorar e propiciar formas de controle do espaço urbano?

\section{5- SISTEMA DE INFORMAÇÕES GEOGRÁFICAS/GEOPROCESSAMENTO E A MODELAGEM}

As cidades possuem uma grande heterogeneidade de feições, o que implica em diferentes formas de intervenção na atmosfera, em consequência, a interface entre a informática e a pesquisa ambiental é importante, onde a vasta variedade de ambientes, envolvendo diferentes dimensões territoriais e a frequente situação de desequilíbrio ambiental demandam diversos tipos de tratamentos dos dados, como os proporcionados pelos Sistemas de informações geográficas (SIG). Os problemas ambientais, aqui explicitados os de ordem climática, têm expressão diversificada em termos taxonômicos e territoriais, sendo possível, criar um modelo digital do ambiente usando geoprocessamento e SIG.

Este modelo permite ter uma visão de conjunto do ambiente, considerando simultaneamente suas características físicas (clima, topografia, hidrografia, declividade), biótica (vegetação), socioeconômicas (aqui considerados os elementos derivados ou influenciados pela ação antrópica no ambiente urbano, como as edificações, taxa de impermeabilização, fator de visão do céu, vias de circulação, áreas verdes, etc), possibilitando operacionalizar em conjunto um grande número de variáveis.

Um modelo digital do ambiente permite analisar áreas pequenas e suas respectivas características ambientais coligidas na sua base de dados, tornando possível uma inspeção detalhada e conjugada dos espaços territorial e taxanômico.

Os SIGs permitem ainda conjugar um grande número de dados, de diferentes naturezas (tipos, escalas, resoluções), pois, o que os integra é a localização, baseada numa base de dados geocodificado, que se destaca no processo de execução, por ser considerado uma ação direta, onerosa e demorada. 
Desta forma, o uso dos SIGs/geoprocessamento, permitem retirar de uma base geocodificada, informações sobre a distribuição territorial da variável e/ou do conjunto de variáveis, permitindo construir simulações, cenários prospectivos e classificar a área em unidades (figura $1)$.

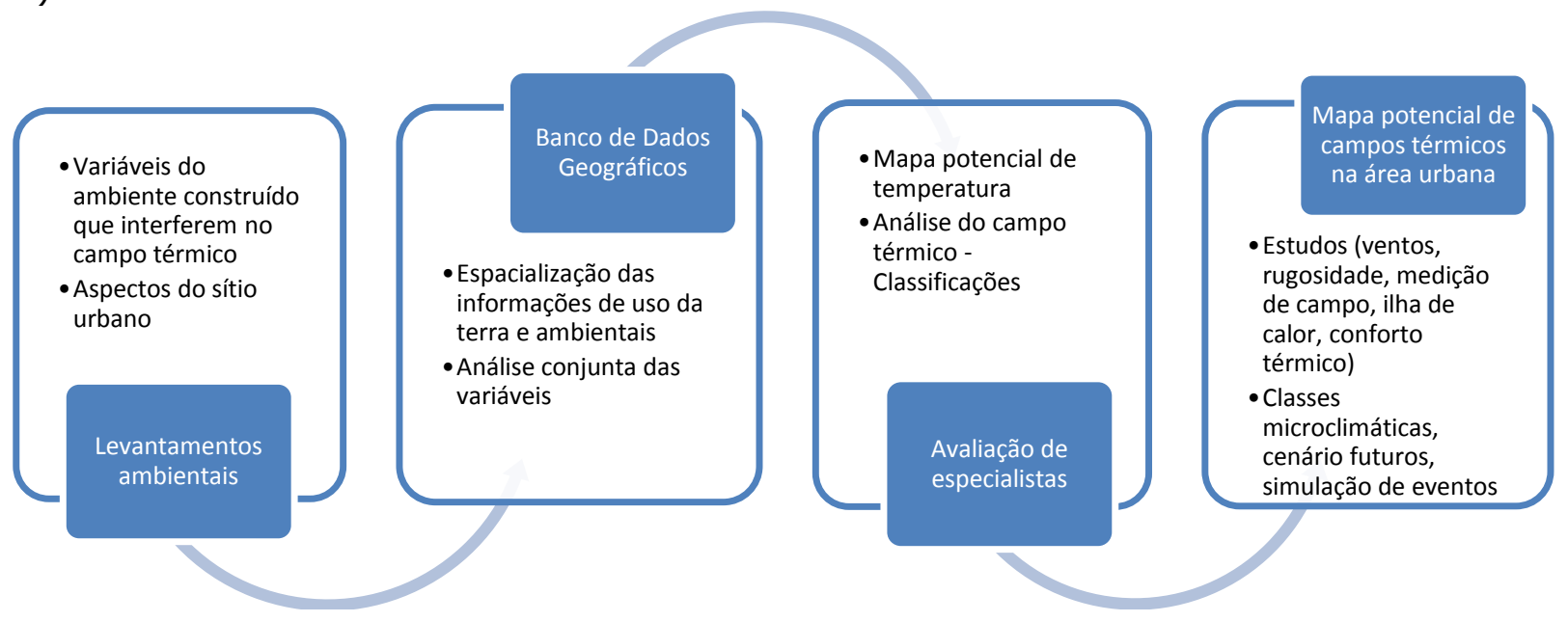

Figura 1- Proposta metodológica baseada em SIG, aplicado ao estudo de campos térmicos. Elaboração: Ferreira, 2014.

\section{1- BASE DE DADOS}

Para o estudo foi criada uma base de dados geocodificada, para a região urbana centro da cidade de Juiz de Fora-MG, na escala de 1:2000, baseada na fotografia aérea de Juiz de Fora, 2007, utilizando o sistema de informação geográfica Arc View 3.2 e Arc Gis 10.

Baseados nesta base de dados foram criados mapas básicos, gerados a partir de dados cedidos pela Prefeitura de Juiz de Fora, dados que foram coletados em campo e outros foram vetorizados diretamente da fotografia aérea da cidade, como pode ser visto na tabela 1.

\begin{tabular}{|c|c|}
\hline Tipo & Fonte/Metodologia \\
\hline \multicolumn{2}{|l|}{ 1- Edificações } \\
\hline \multicolumn{2}{|l|}{ a) Formas } \\
\hline Altura das edificações & Base de dados PJF; RIBEIRO et al. (2010) \\
\hline Distância entre as edificações & Fotografia Aérea (2007); Vetorização manual \\
\hline Sombreamento & RIBEIRO et al. (2010); Fotografia Aérea (2007) \\
\hline Cânyons urbanos & Fotografia Aérea (2007); Vetorização manual \\
\hline Geometria urbana & $\begin{array}{l}\text { Fotografia Aérea (2007); Vetorização manual; MENDONÇA e } \\
\text { ASSIS (2003) }\end{array}$ \\
\hline Fator visão do céu & SOUZA (2003); Fotografia Aérea (2007) \\
\hline Massa Construída & TSO et al. (1990); Fotografia aérea (2007) \\
\hline \multicolumn{2}{|l|}{ b) Materiais de Construção } \\
\hline Revestimento & Base de dados PJF; Fotografia aérea (2007) \\
\hline Tipo de cobertura & Base de dados PJF; Fotografia aérea (2007) \\
\hline Cor & Base de dados PJF; Fotografia aérea (2007) \\
\hline Albedo & $\begin{array}{l}\text { Base de dados PJF; Fotografia aérea (2007); FERREIRA E ASSIS } \\
\text { (2014) }\end{array}$ \\
\hline Emissividade & $\begin{array}{l}\text { Base de dados PJF; Fotografia aérea (2007); FERREIRA E ASSIS } \\
\text { (2014) }\end{array}$ \\
\hline \multicolumn{2}{|c|}{ 2- PAVIMENTO } \\
\hline \multicolumn{2}{|c|}{ a) Ruas, Avenidas e Estradas } \\
\hline Largura & Fotografia Aérea (2007); Vetorização manual \\
\hline Tipo & Fotografia Aérea (2007); Vetorização manual \\
\hline Superfície impermeável & Fotografia Aérea (2007); Vetorização manual \\
\hline \multicolumn{2}{|l|}{ b) Áreas Verdes } \\
\hline Área & Fotografia Aérea (2007); Vetorização manual \\
\hline
\end{tabular}


Revista Brasileira de Climatologia

ISSN: 1980-055x (Impressa) 2237-8642 (Eletrônica)

\begin{tabular}{|c|c|}
\hline Tipo de vegetação & Fotografia Aérea (2007); Vetorização manual \\
\hline Sombreamento & RIBEIRO et al. (2010); Fotografia Aérea (2007) \\
\hline \multicolumn{2}{|l|}{ c) Espaços Livres } \\
\hline Tipo & Fotografia Aérea (2007); Vetorização manual \\
\hline Área & Fotografia Aérea (2007); Vetorização manual \\
\hline \multicolumn{2}{|r|}{ 年, } \\
\hline Tipo & Fotografia Aérea (2007); Vetorização manual \\
\hline Área & Fotografia Aérea (2007); Vetorização manual \\
\hline \multicolumn{2}{|l|}{ 3- POLUIÇÃO DO AR } \\
\hline $\begin{array}{l}\text { Fluxos de veículos automotores } \\
\text { (caminhões, carros e ônibus) }\end{array}$ & GETRAN; Levantamento de campo \\
\hline \multicolumn{2}{|l|}{ 4- SÍTIO URBANO } \\
\hline Taxa de impermeabilização & Fotografia Aérea (2007); \\
\hline Topografia & $\begin{array}{l}\text { Modelo Digital do Terreno; Fotografia } \\
\text { levantamento topográfico PJF. }\end{array}$ \\
\hline Declividade & $\begin{array}{l}\text { Modelo Digital do Terreno; } \\
\text { levantamento topográfico PJF. }\end{array}$ \\
\hline
\end{tabular}

Tabela 1- Relação das variáveis utilizadas, suas fontes e bases metodológicas.

Elaboração: Ferreira, 2014.

O desenvolvimento deste modelo consistiu em integrar uma análise teórica, quantitativa e qualitativa, afim de, obter uma identificação de áreas potencialmente quentes ou frias, em função da disposição, morfologia, geometria, estrutura e formas urbanas.

Primeiramente, a metodologia proposta partiu da identificação das características e variáveis que iriam interferir na hipótese de "potencial térmico". Esta identificação passou por uma revisão bibliográfica de artigos, dissertações, teses e livros que faziam uma análise das características térmicas na cidade, englobando investigações sobre ilha de calor e frescor, campos térmicos, conforto térmico, inversão térmica, etc. e quais variáveis eram consideradas pelos autores como sendo importantes na definição e interferência das temperaturas no ambiente urbano.

A partir deste procedimento, foram levantadas as variáveis (tabela 1 e 2) que constituíram de base de informação, para o modelo que tem como objetivo definir áreas com campos térmicos diferentes, em função das distintas formas de uso e apropriação do espaço urbano.

Neste processo foram criados uma série de mapas básicos, que foram utilizados na construção de mapas temáticos estes após serem reclassificados, foram sobrepostos e formaram um mapa síntese da área em estudo (tabela 2).

\begin{tabular}{|c|c|c|}
\hline MAPAS BÁSICOS & MAPAS TEMÁTICOS & $\begin{array}{c}\text { MAPA } \\
\text { SÍNTESE }\end{array}$ \\
\hline Altura das edificações & \multirow{7}{*}{$\begin{array}{l}\text { 1. Massa construída } \\
\text { 2. Fator de visão do céu } \\
\text { 3. Sombreamento }\end{array}$} & \multirow{17}{*}{$\begin{array}{l}\text { Potencial } \\
\text { térmico }\end{array}$} \\
\hline Densidade de construção & & \\
\hline Distância das edificações & & \\
\hline Quadras & & \\
\hline Lotes & & \\
\hline Direção predominante das construções & & \\
\hline Cânions Urbanos & & \\
\hline Revestimento das edificações e pavimentos & \multirow{3}{*}{$\begin{array}{l}\text { 4. Albedo } \\
\text { 5. Emissividade }\end{array}$} & \\
\hline Cor das edificações e pavimentos & & \\
\hline Tipo de cobertura das edificações & & \\
\hline Largura das vias & \multirow{3}{*}{$\begin{array}{l}\text { 6. Ventilação } \\
\text { 7. Calor antrópico/poluição }\end{array}$} & \\
\hline Tipo de vias & & \\
\hline Fluxo de veículos & & \\
\hline Área das áreas verdes, água & \multirow{4}{*}{$\begin{array}{l}\text { 8. Áreas verdes e água } \\
\text { 9. Taxa de impermeabilização }\end{array}$} & \\
\hline Área de influência & & \\
\hline Tipo de áreas verdes, água & & \\
\hline Densidade habitacional/edificação & & \\
\hline
\end{tabular}

Tabela 2- Sequência de mapas básicos, temáticos e de síntese utilizados no modelo.

Elaboração: Ferreira, 2014. 
A espacialização de cada variável foi feita separadamente, associadas a cada lote. Afim de, maximizar o detalhamento e o grau de interferência, subdividindo a área, em função da característica analisada (albedo, massa construída, sombreamento, etc.). Todos os mapas foram classificados em 5 classes, posteriormente, foram associados valores numéricos de acordo com o grau de influência no comportamento da temperatura.

A superposição de todas as características levantadas ocorreu a partir da formulação de uma matriz de potencial térmico, onde são somados os valores pré-estabelecidos de todas as variáveis. Este procedimento foi realizado no ArcGis 10 (Figura 2).

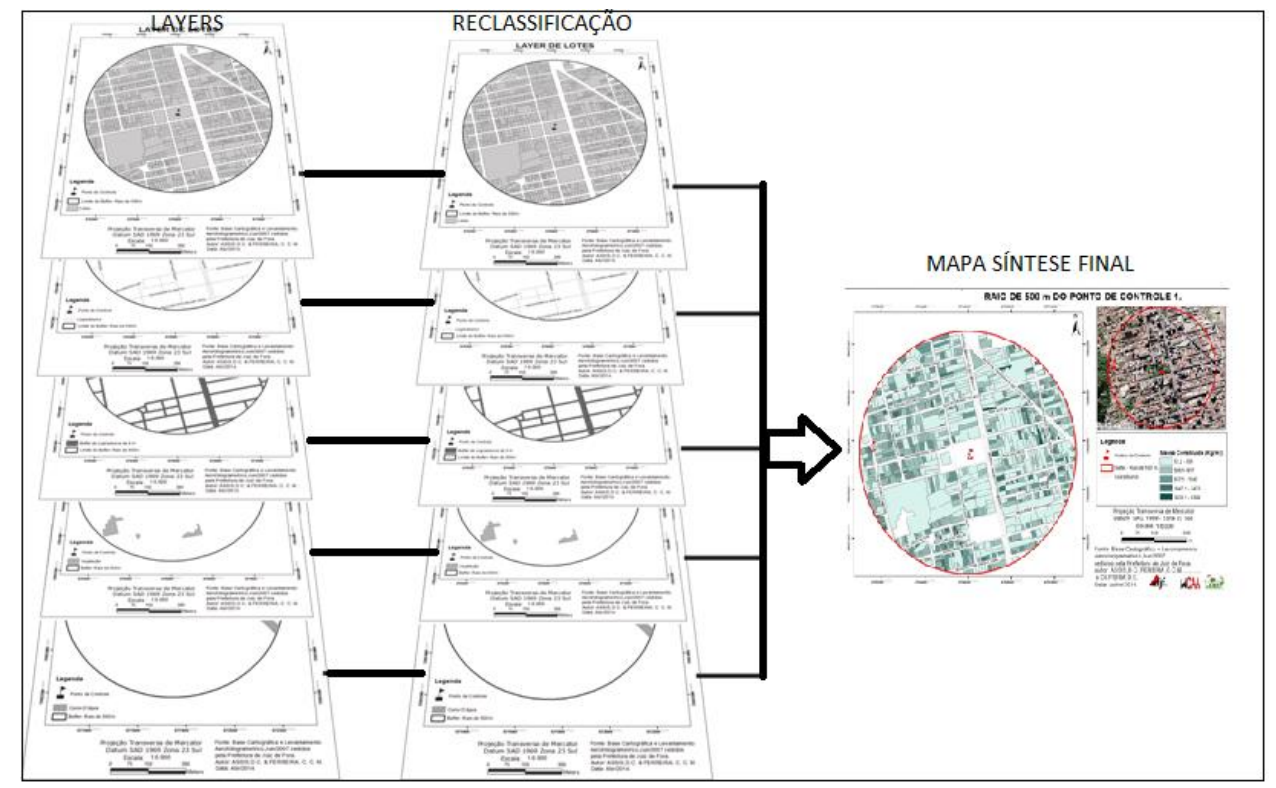

Figura 2 - Operação dos mapas no SIG

Elaborado: Ferreira, 2014.

A matriz possui um caráter qualitativo, pois os valores atribuídos a cada classe dependerá da forma de análise e interpretação quanto ao grau/peso de influência da variável no comportamento da temperatura. Nela são cruzadas as características de cada uma das variáveis trabalhadas em função do novo valor numérico que foi atribuído, que representa o grau/peso de influência de cada uma delas no comportamento da temperatura (tabela 2).

A espacialização destas informações consistiu na reclassificação dos mapas, em função destas novas categorias (tabela 3 ).

\begin{tabular}{|c|c|c|c|c|c|}
\hline \multicolumn{6}{|c|}{ Variáveis e pesos } \\
\hline \multicolumn{2}{|c|}{$\begin{array}{c}\text { Massa Construída } \\
\left(\mathrm{Kg} / \mathrm{m}^{2}\right)\end{array}$} & \multicolumn{2}{|c|}{ Albedo } & \multicolumn{2}{|c|}{ Emissividade } \\
\hline Variável & Peso & Variável & Peso & Variável & Peso \\
\hline $37,6-506$ & 1 & Telha metálica & 1 & Telha metálica & 5 \\
\hline $506,1-917$ & 2 & Telha cerâmica & 1 & Telha cerâmica & 2 \\
\hline $917,1-1647$ & 3 & Fibrocimento & 3 & Fibrocimento & 2 \\
\hline $1647,1-3433$ & 4 & Laje & 2 & Laje & 2 \\
\hline \multirow[t]{3}{*}{$3433,1-8328$} & 5 & Asfalto & 5 & Asfalto & 2 \\
\hline & & Vegetação & 2 & Vegetação & 1 \\
\hline & & Água & 2 & Água & 2 \\
\hline \multicolumn{2}{|c|}{ Fator de Visão do Céu \% } & \multicolumn{2}{|c|}{ Áreas verdes } & \multicolumn{2}{|c|}{ Sombreamento } \\
\hline Variável & Peso & Variável & Peso & Variável & Peso \\
\hline $0-20$ & 5 & Área verde & 1 & $0-20$ & 1 \\
\hline $21-40$ & 4 & Buffer de $50 \mathrm{~m}$ & 3 & $21-40$ & 2 \\
\hline $41-60$ & 3 & Área construída & 5 & $41-60$ & 3 \\
\hline
\end{tabular}


Revista Brasileira de Climatologia

ISSN: 1980-055x (Impressa) 2237-8642 (Eletrônica)

\begin{tabular}{|c|c|c|c|c|c|}
\hline $61-80$ & 2 & & & $61-80$ & 4 \\
\hline $81-100$ & 1 & & & $81-100$ & 5 \\
\hline \multicolumn{2}{|c|}{ Água } & \multicolumn{2}{|l|}{ Ventilação } & \multicolumn{2}{|c|}{ Poluição (carros/minuto) } \\
\hline Variável & Peso & Variável & Peso & Variável & Peso \\
\hline Curso d'água & 1 & $\begin{array}{ll}\text { Via } & \text { arterial } \\
\text { secundária } & \\
\end{array}$ & 1 & $0-7$ & 1 \\
\hline Buffer de $50 \mathrm{~m}$ & 3 & Via coletora principal & 2 & $8-15$ & 2 \\
\hline \multirow[t]{3}{*}{ Área Construída } & 5 & Via local principal & 3 & $16-23$ & 3 \\
\hline & & Via local secundária & 4 & $24-32$ & 4 \\
\hline & & Via de pedestres & 5 & $<33$ & 5 \\
\hline \multicolumn{2}{|c|}{$\begin{array}{ll}\text { Taxa } & \text { de } \\
\text { Impermeabilização } & \end{array}$} & Topografia & & & \\
\hline Variável & Peso & Variável & Peso & Variável & Peso \\
\hline Permeável & 1 & $672-680$ & 5 & & \\
\hline \multirow[t]{6}{*}{ Impermeável } & 5 & $681-700$ & 5 & & \\
\hline & & $701-730$ & 4 & & \\
\hline & & $731-760$ & 3 & & \\
\hline & & $761-790$ & 2 & & \\
\hline & & $791-810$ & 1 & & \\
\hline & & $811-840$ & 1 & & \\
\hline
\end{tabular}

Tabela 3- Valores numéricos associados às variáveis.

Fonte: Organizado por Ferreira (2014).

Todos os mapas foram classificados em 5 classes e em função do potencial de aquecimento da variável em questão, estes mapas foram reclassificados recebendo notas de 1 a 5 , sendo o valor numérico 1 , dado para a classe que possui menor potencial térmico (como exemplo, uma densa área verde, levaria o valor 1 ) e para as que possuem um alto potencial de aquecimento (como por exemplo, um asfalto novo, com baixo albedo) levaria o valor 5 . Este procedimento é realizado para cada classe e variável. Posteriormente são dados pesos em função da importância e representatividade no aquecimento/resfriamento urbano. Ganhando uma análise hierárquica do grau de importância entre as classes de uma variável (Tabela 3).

Ao final é gerado um mapa síntese, que representa o grau que o ambiente físico/construído tem de influenciar na temperatura, denominado no mapa de pesos, no qual, com a soma de todos os mapas, quanto maior o peso, maior será as condições do ambiente em produzir temperaturas mais elevadas e quanto menor, as temperaturas tenderiam a ser mais baixas.

Por fim, para testar e validar o modelo, foi analisado o mapa síntese final com um levantamento da temperatura do ar nas áreas trabalhadas (Figura 3). Para compararmos os resultados alcançados, com os dados reais registrados em superfície, foi utilizada a área de influência em torno das estações. Pois, segundo Oke (2004) a área de influência de uma estação de medição não é um raio simétrico, é uma elipse, determinada pela direção predominante do vento. Sendo o raio de influência da temperatura do ar, em torno de $0,5 \mathrm{~km}$ em média dependendo do grau de densidade da área. Desta forma, foi utilizado um raio de 0,5 $\mathrm{km}$ no entorno de 2 pontos de controle para estudo e levantamento das variáveis do ambiente físico urbano (Figura 4). 


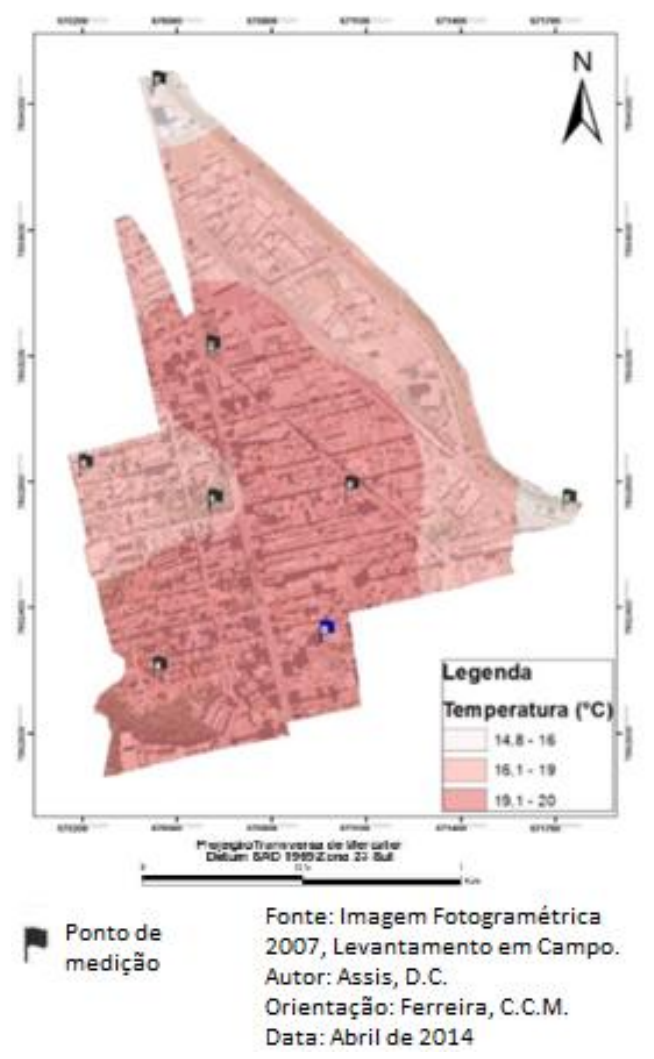

Figura 3- Mapa da Temperatura do ar da Região Urbana Centro de Juiz de Fora-MG

\section{5- RESULTADOS E DISCUSSÃO}

\section{1- A CIDADE, SEU SÍtTIO E O CLIMA URBANO}

A cidade de Juiz de Fora está localizada na Zona da Mata Mineira, a $43^{\circ} 20^{\prime} 40^{\prime \prime} \mathrm{O}$ e a $21^{\circ} 41^{\prime} 40^{\prime \prime} \mathrm{S}$ (Figura 1). Esta, primeiramente ocupou um vale de fundo chato, com aproximadamente $600 \mathrm{~m}$ de largura, formado pelo Rio Paraibuna (MARTINS, 1996). Este rio corta o município no sentido NW-SE, encaixando-se em um terraço alveolar, estabelecido a partir de um fraturamento transversal, aonde estabelece a região centro da cidade de Juiz de Fora (Figuras 4 e 5).

A morfogênese gerou principalmente duas formas diferentes de relevo, constituindo basicamente nos terraços fluviais e as elevações. Estas formas tiveram uma importante função no processo de expansão urbana, pois, inicialmente a ocupação urbana ocorreu ao longo do vale do rio Paraibuna e de seus afluentes. Consequentemente a principal direção da ocupação urbana, é a mesma do vale formado pelo rio Paraibuna, que segue o seu sentido NW-SE, com altitudes entre 800 e $900 \mathrm{~m}$. As áreas com altitudes maiores que $900 \mathrm{~m}$, estão dispostas de forma irregular, tendo maior incidência na porção nordeste da cidade. As superfícies com 800$900 \mathrm{~m}$ estão atreladas às planícies alveolares, com grande ocupação demográfica, sendo ainda, consideradas áreas de expansão urbana, como a porção oeste e nordeste da cidade. 


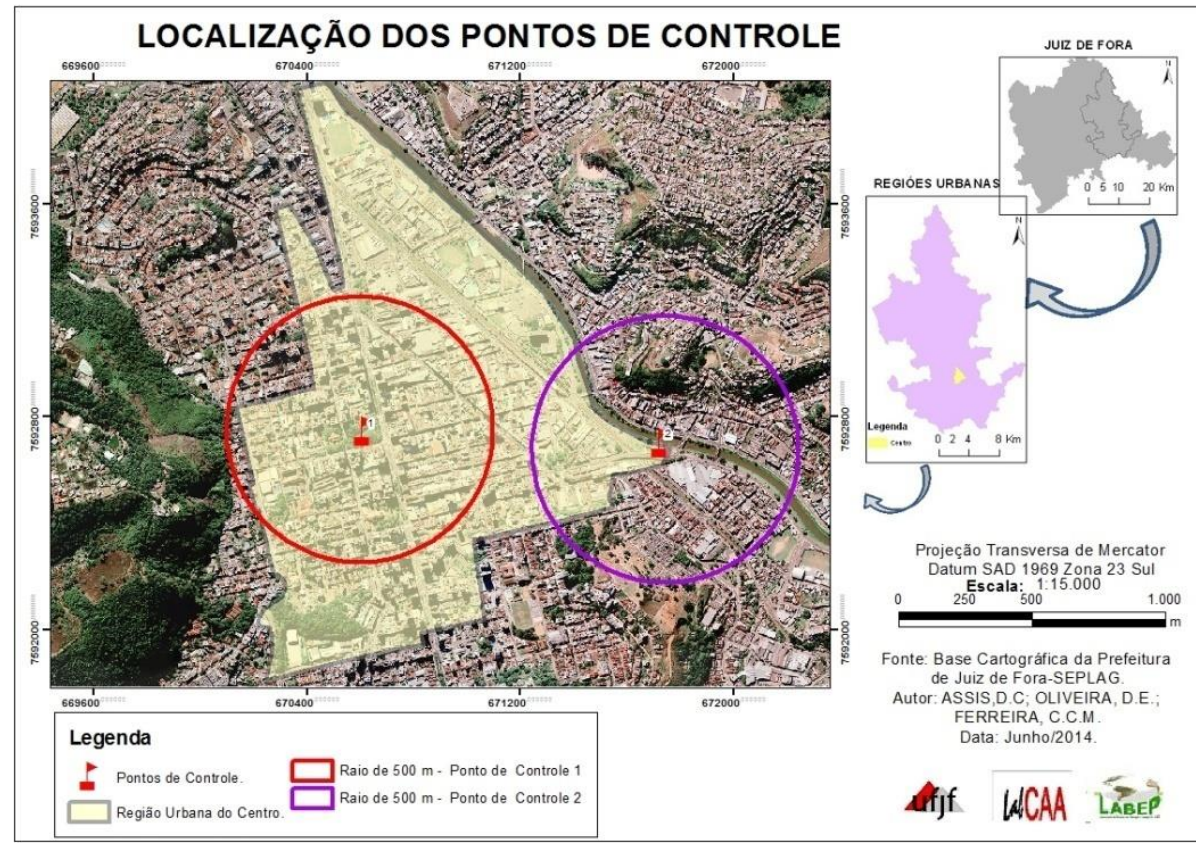

Figura 4- Localização dos pontos de Observação e área de estudo

Desta forma, o Rio Paraibuna e seus afluentes, são importantes e delinearam o processo de ocupação do sítio urbano, pois nos terraços ocorrem as zonas com menor declividade e, portanto a área que primeiramente foi ocupada. Os vales foram ocupados não respeitando a área de inundação do leito do rio, o que desencadeia enchentes, que se sucedem todos os anos no período das chuvas (Figura 5).

Ao lado dos terraços, erguem-se as elevações, que também influenciam o processo de ocupação, pois inicialmente eram consideradas obstáculos, em função das altas declividades, alcançando 50\%. Segundo Martins (1996, p.43) "a presença de grande número de encostas íngremes, que em algumas áreas tomam aspecto de formações de "mar de morro", condicionou o surgimento ilhado da ocupação, não permitindo, ao observador, uma percepção de conjunto do sítio urbano, exceto na direção dos vales com terraços mais amplos, ou dos pontos estratégicos de algumas elevações".

A ocupação das encostas ocorre principalmente pós a saturação dos vales e em função do alto valor imobiliário, a população começa a ocupar as encostas, este processo é acompanhado do desmatamento, que em muitos casos desencadeou processos erosivos, e em função da sazonalidade da precipitação, que possui uma maior concentração na primavera/verão, intensificou as erosões, gerando voçorocas e sucessivos movimentos de massa, que assolam a cidade todos os anos.

Estes eventos cresceram com o aumento da população urbana, que ocupou primeiramente, 0 que hoje é considerado o centro da cidade e posteriormente as regiões periféricas. Este processo levou a área central apresentar múltiplos usos do solo, consorciando funções residenciais, comerciais e industrial. Passam ainda pela área central, vias de grande fluxo de veículos automotivos, como a Av. Barão do Rio Branco, Av. Getúlio Vargas, Av. Brasil e Av. Presidente Itamar Franco. Segundo Oliveira (2006, p.56) aproximadamente 31 mil pessoas, provindas das cidades vizinhas, circulam diariamente em Juiz de Fora. Pois esta polariza os fluxos da Microrregião de Juiz de Fora, Além Paraíba, Cataguases, Barbacena, Muriaé e Ubá, com suas respectivas áreas de polarização. Soma-se a todas estas questões a presença de uma alta densidade de construções, com aproximadamente $30 \mathrm{~m}$ de altura, sem apresentar afastamento entre as edificações, o que leva a presença de canyons urbanos, configurando características microclimáticas distintas. 


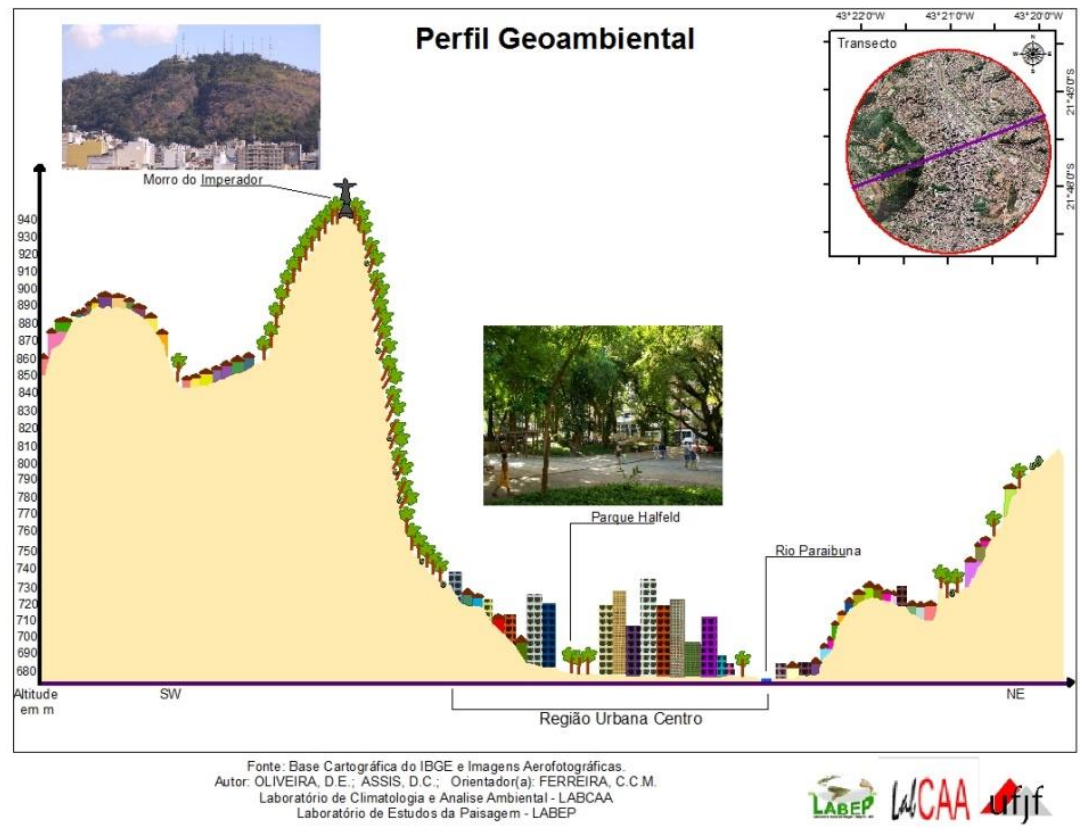

Figura 5- Perfil geoambiental, corte sw/nw, evidenciando a Região urbana centro da cidade de Juiz de Fora-MG.

O sítio urbano da cidade de Juiz de Fora, seja pela diferença altimétrica, que em alguns pontos chega a $300 \mathrm{~m}$, ou pela forma e estrutura urbana, apresenta a possibilidade de configurar condições microclimáticas distintas. Essas diferenças, já foram investigadas por Martins (1996) quando verificou a existência de ilha de calor na cidade. E por Borges et al. (2009) que analisou a temperatura do ar na cidade, identificando que as maiores temperaturas estavam associadas as áreas de maior adensamento urbano, localizadas nas áreas centrais e sudeste da cidade. E ainda por Oliveira et al. (2008) que comparou os dados de duas estações meteorológicas automáticas, uma localizada no centro da cidade a $675 \mathrm{~m}$ de altitude e outra localizada na região Oeste, mais periférica e a $970 \mathrm{~m}$ de altitude, verificaram a existência de uma ilha de calor na região central, moderada no período da manhã e mais acentuada ao anoitecer.

\section{2- AS VARIÁVEIS, O MAPA SÍNTESE E OS CAMPOS TÉRMICOS}

O modelo proposto está balizado em um conjunto de variáveis, que seriam importantes na definição e influenciariam na temperatura do ar local, criando, consequentemente, campos térmicos distintos na área urbana. Desta forma, as variáveis utilizadas foram organizadas em dois grupos, um relacionado à produção de calor (albedo, emissividade, verticalização, massa construída, poluição do ar, fator visão do céu e taxa de impermeabilização) e o que está atrelado à mitigação (áreas verdes, água, ventos e sombreamento). Cada uma destas variáveis foi considerada em função do seu potencial a maximizar ou minimizar a temperatura do ar.

Desta forma, analisando os mapas temáticos gerados, em função da prerrogativa de serem importantes no aquecimento urbano, destacamos que a presença predominante de pavimentos asfálticos e coberturas com baixo albedo e baixa emissividade como as lajes tendem a ter a sua temperatura mais elevada, as lajes envelhecidas foram o tipo de cobertura mais presente nos dois pontos analisados, chegando a compreender em torno de 30 a $13 \%$ das áreas analisadas.

As telhas metálicas apresentam uma temperatura de até $57,9^{\circ} \mathrm{C}$ (GARTLAND, 2010) sob o sol e um albedo de 0,57, estas mesmo apresentando um albedo mais alto, alcança uma temperatura elevada em função da baixa emissividade. O que implica em uma troca de calor entre a telha metálica e o ambiente, influenciando na temperatura do ar. Este tipo de 
cobertura teve uma representatividade que variou de 2 a $10 \%$ das áreas analisadas. Sendo que esta foi mais representativa no ponto 2 .

Por outro lado, áreas verdes, compostas por árvores, herbáceas ou arbustos e cursos d'água, tendem a se manter frescas sob o sol. A vegetação mantém a sua temperatura igual ou inferior à temperatura do ar, sob condições ideais de hidratação (GARTLAND, 2010). Os dois pontos analisados possuem em torno de $6 \%$ da área. De acordo com Oke (1978), seria recomendado para proporcionar balanço térmico adequado às áreas urbanas um índice mínimo de cobertura vegetal de $30 \%$ em relação à área total. Ressalta, ainda, que valores inferiores a $5 \%$ determinariam características semelhantes à de um deserto.

A água e a vegetação apresentam alto albedo e emissividade mostrando sua eficiência em manter os ambientes mais frescos. A presença da vegetação e do curso d'água redundou em regiões com temperaturas mais amenas, como pode ser observado na figura 3.

A cobertura asfáltica no ponto 2 foi a que apresentou maior área com 35\%. Sendo o asfalto o pavimento mais utilizado na pavimentação das ruas e avenidas da cidade. Conhecido pelo seu baixo albedo e alta emissividade, tem uma grande influência na temperatura do ar. Repercutindo em um ambiente mais quente. Nos demais pontos o asfalto ocupa o segundo revestimento mais presente na área.

Desta forma, o albedo ou refletância dos materiais utilizados em coberturas de edifícios e pavimentos, é uma das variáveis responsáveis por seu ganho de calor. Logo, a presença predominante no urbano de pavimentos asfálticos e coberturas com baixo albedo e em alguns casos baixa emissividade tendem a ter a sua temperatura mais elevada, o que ocasiona em uma transferência de calor para o seu entorno, propiciando um aumento na temperatura do ar. Por outro lado, superfícies com alto albedo e emissividade permanecem frias, mesmo quando expostas a radiação solar e consequentemente, transmitem menos calor para às suas adjacências.

Outra variável analisada foi o Fator de Visão do Céu, que estabelece que quanto mais obstruído é um local na área urbana, maior é a obstrução do céu, e maior será a dificuldade do ambiente em dispersar a energia térmica armazenada para a atmosfera (Oke, 1986). Este processo ocorre, porque a verticalização associada a morfologia urbana aumentam a superfície de contato exposta a radiação, ocasionando aumento da absorção da radiação solar. Além de estabelecer o período que a superfície estará exposta a radiação solar direta. O ponto 1 apresenta maior obstrução, quando comparado ao ponto 2 .

A taxa de impermeabilização do solo que em todos os pontos analisados são elevados, sendo menor no ponto 2, Oke $(1982,1988)$ destaca que a principal diferença entre os processos térmicos presentes na área urbana e seu entorno rural, está na distribuição dos fluxos turbulentos de calor sensível e de calor latente, no qual o clima urbano, em função do ambiente densamente construído e impermeabilizado, teriam um comportamento diferente do ambiente rural, vegetado. Desta forma, as áreas urbanas perdem menos calor por meio do resfriamento evaporativo, pois são compostas principalmente por áreas impermeáveis e composto por superfícies com maior capacidade térmica, levando a uma maior parte do fluxo térmico é de calor sensível. Os equipamentos urbanos possibilitam um maior estoque de calor durante o dia e no período da noite, a intensidade da perda térmica está relacionada à quantidade de calor armazenado e disponibilizado pela superfície. A taxa de impermeabilização nos remete a analisar diversos parâmetros significativos para o controle e limite da expansão urbana com o objetivo da sustentabilidade, tais como: densidade de população e de habitações, disponibilidade de área verde, disponibilidade de serviços de infra-estrutura urbana, qualidade da água, do ar.

A disposição e largura das vias de circulação foram trabalhadas em função da sua capacidade de ventilação, pois estas em função da sua largura tendem a canalizar os ventos, quando dispostas na direção predominante dos ventos, que no caso da cidade de Juiz de Fora, é no quadrante Norte. Desta forma, as vias compostas pela Av. Barão do Rio Branco, que possui uma alta verticalização nas suas bordas, tende a apresentar uma maior velocidade do vento do 
que as ruas que possuem um traçado leste/oeste, estas em função do seu traçado deveriam receber maior radiação solar direta ao longo do dia, porém em função dos altos edifícios, ocorre um sombreamento nas ruas durante a maior parte do dia. Logo, por serem mais estreitas e normalmente ladeada por edifícios, encostados uns aos outros, sem quase nenhum tipo de ventilação entre eles, com aproximadamente $30 \mathrm{~m}$ de altura, acabam por caracterizar cânions urbanos, reduzindo a velocidade dos ventos e dos processos convectivos, o que pode ocasionar aumento no armazenamento de calor. Estas ruas, também são caracterizadas por alto fluxo de veículos automotores o que pode ocasionar na geração de poluição do ar e consequente ganho de temperatura. Esta situação está bem representada no ponto 1.

A Av. Brasil importante via de acesso e circulação da cidade, se comporta como um corredor de vento, pois além de ter um traçado no sentido noroeste/sudeste, foi construída às margens do rio Paraibuna, sendo caracterizada por um corredor de vento, com maior recepção de radiação solar direta, esta situação está bem caracterizada no ponto 2 .

Porém, as vias de circulação também são influenciadas pelo fluxo de veículos automotores, que por sua vez fornecem calor antrópico pela combustão, além da poluição do ar, o que pode ocasionar aumento da temperatura em ambientes que estão expostas a um intenso fluxo de automóveis. Essa situação foi verificada, principalmente no ponto 1 que congrega a área mais densamente construída, com vias de intenso fluxo de automóveis, sendo parte delas apresentando baixa largura, o que gera um constante engarrafamento e liberação de calor, associado a verticalização e formação de Cânions urbanos. O ponto 2 apesar de apresentar vias de grande circulação estas estão associadas a áreas mais amplas e consequente maior capacidade de dispersão da poluição do ar.

Quando comparado o mapa síntese (Figuras 6 e 7) de cada ponto controle, verificamos uma similaridade ao registro de temperatura do ar (Figura 3), realizado em superfície, constatando que o modelo proposto, indica uma situação próxima à realidade, isto é foi capaz de discriminar as áreas que possuem temperaturas distintas em função, principalmente, das diferentes formas, usos e ordenamento da área urbana. Destacando que os valores presentes na legenda de 1 ao 5, representam o potencial da área em registrar temperaturas mais elevadas, isto é, quanto maior o valor, maior seria a temperatura do ar naquele local. Nota-se que no ponto 1 (Figura 6), que representa a área urbana com maior massa construída, vias de circulação com maior número de veículos e maior taxa de impermeabilização, menor densidade de áreas verdes, menor albedo, maior emissividade, é a que apresenta maior área com potencial térmico, isto é, que alcançaria maiores temperaturas. 0 ponto 2 (Figuras 7 ) está às margens do Rio Paraibuna e de duas importantes avenidas de circulação de veículos automotores. Apresenta média massa construtiva, maior recepção da radiação solar direta, maior ventilação e consiste na área que apresenta intermediário potencial térmico, situação esta similar ao que foi constatado no registro da temperatura do ar em superfície nestes locais (Figura 3), acrescentando que no ponto 2 ocorreu a maior incidência da classe 1 e 2, que se caracterizam pelo potencial térmico menor. 

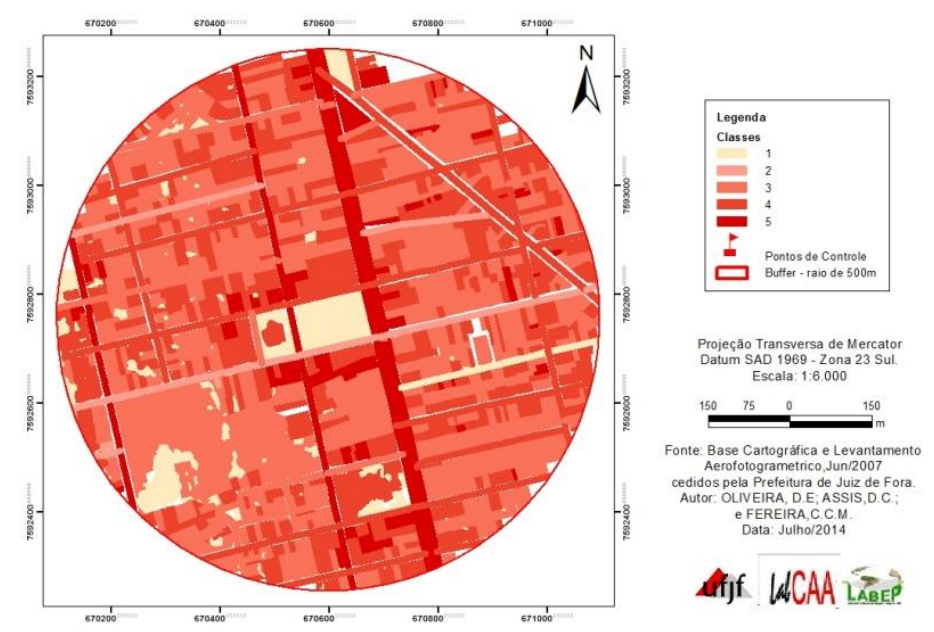

afif. WCAA $\overline{\text { LBBE? }}$

Figura 6- Mapa Síntese do ponto de controle 1.

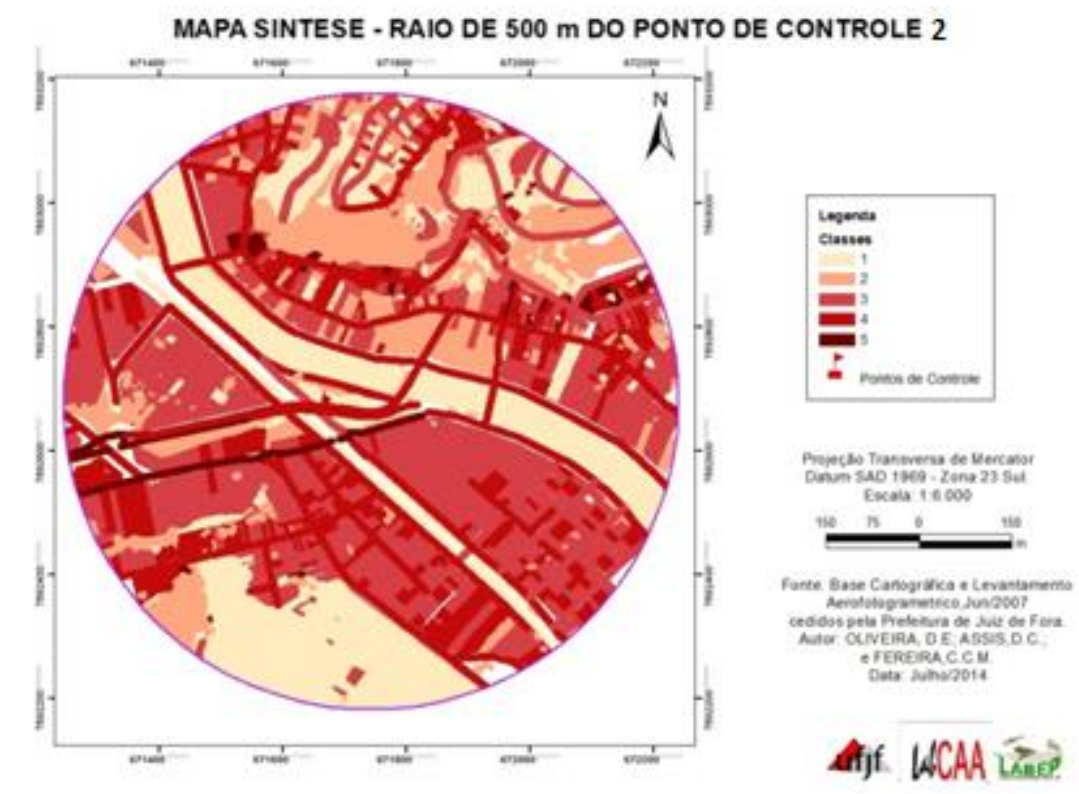

Figura 7- Mapa Síntese do ponto de controle 2.

\section{6- CONCLUSÕES}

De acordo com a metodologia proposta e os resultados alcançados, destacamos, que o uso do Sistema de Informações Geográficas, na análise e principalmente no processo de geração de informações, mapas básicos, temáticos e de síntese, possibilitou a execução do modelo e principalmente a manipulação dos dados viabilizando integrar dados e informações quantitativas e qualitativas.

A área que a metodologia foi testada se caracteriza pela densidade de ocupação, fluxo de veículos e pessoas, verticalização, etc, o que foi evidenciado pela espacialização e quantificação das variáveis trabalhadas, entretanto algumas considerações podem ser apontadas, com relação às áreas analisadas, destacando que uma política de planejamento e gestão urbana, poderiam estabelecer critérios de uso e ocupação, em função das características já presentes no processo de ocupação urbana, evitando, por exemplo, maior adensamento, substituição dos revestimentos e cores das edificações, minimizando absorção 
ISSN: 1980-055x (Impressa) 2237-8642 (Eletrônica)

de calor, maximizando áreas verdes e plantio de árvores, aumentando sombreamento e absorção de calor latente, enfim, contribuindo para melhorar as condições de conforto e qualidade de vida nas cidades.

Constata-se, portanto que a configuração geométrica da área urbana, em função da disposição, altura, densidade dos edifícios e demais elementos urbanos e a inércia térmica das superfícies, caracterizada pela capacidade dos materiais interagirem com as temperaturas do meio que as rodeia e armazenando ou refletindo a radiação incidente, são extremamente relevantes na alteração das características climáticas locais, podendo levar a formação de ilhas de calor e deveriam ser consideradas no planejamento e gestão urbanos, pois levaria a uma cidade mais saudável e sustentável.

Apesar de termos mostrado um modelo aplicado a um estudo de caso, este foi sistematizado e organizado de forma a viabilizar adaptações para outras localidades, com realidades distintas da estudada, além de viabilizar integrar outro conjunto de informações/dados.

\section{7- BIBLIOGRAFIA}

ALCOFORADO, M.J.; ANDRADE, H.; LOPES, A.; VASCONCELOS, J. Application of climatic guidelines to urban planning: the example of Lisbon (Portugal). Landscape and Urban Planning. v. 90, 2009, p. 56-65.

AMORIM, M.C.C.T. Ilhas de calor em Birigui-SP. Revista Brasileira de Climatologia, Presidente Prudente, v.1, n.1, 2005. p. 121-130.

ANDREOTI, C. E. Comparação microclimática entre dois imóveis nos municípios de São Paulo e São Roque. Revista Geográfica Acadêmica, Goiás, v. 3, n.2, Dezembro de 2009.

ARONOFF, S. Geographic information systems: a management perspective. Ottawa: DL Publications, 1989.

ASSIS, W.L. Análise do campo térmico e hígrico em Belo Horizonte. Dissertação (Mestrado em Geografia), Instituto de Geociências da UFMG, Belo Horizonte, 2001.

BAI, Y; MIKAMI, T. Measurement and mitigation of urban heat island in Shanghai, China. In: INTERNACIONAL CONFERENCE ON URBAN CLIMATE. 6, 2006, Göteborg. Preprints...Göteborg: IAUC, 2006. p. 362-365.

BAUMÜLLER J, REUTER U. Demands and Requirements on a Climate Atlas for Urban Planning and Design. Office of Environmental Protection: Stuttgart, 1999.

BAUMÜLLER J. Implementation of climatic aspects in urban development: the example Stuttgart. In Paper Presented at the Urban Climate + Urban Greenery. 42-52, PGBC, Hong Kong, 2006.

BORGES, V.V.; ZAIDAN, R.T.; MARTINS, L.A. Mapeamento, zoneamento e análise termal por sensoriamento remoto no município de Juiz de Fora, MG. In: XIII Simpósio Brasileiro de Geografia Física Aplicada, 2009, Viçosa. A Geografia Física Aplicada e as Dinâmicas de Apropriação da Natureza. Viçosa: EDUFV, 2009, p. 1-8.

BORNSTEIN, R., STYRBICKI-IMAMURA, R., GONZÁLEZ, J.E., LEBASSI, B., Interactions of Global-Warming and Urban Heat Islands in Different Climate-Zones. In: Fernando, H. J. S., Klaid, Z., McCulley, J.L. (eds), National security and human health implications of climate change. Nato science for peace and security series C: environmental security, chapter 5, Dordrecht, Netherlands, Springer, 2012. 
BRANDÃO, A. M. de P. M. O clima urbano da cidade do Rio de Janeiro. São Paulo, 1996. 362p. Tese (Doutorado em Geografia). Faculdade de Filosofia Letras e Ciências Humanas, Universidade de São Paulo, 1996.

BRANDÃO, A.M.P.M. As alterações climáticas na área metropolitana do Rio de Janeiro: uma provável influência do crescimento urbano. In: ABREU, M.A. (Org.): Natureza e sociedade no Rio de Janeiro. 3ed. Rio de Janeiro: Secretaria Municipal de Cultura, turismo e esportes/Departamento geral de documentação e informação cultural, p. 143-191, 1992.

BRANDÃO, A.M.P.M. Tendências e oscilações climáticas na área metropolitana do Rio de Janeiro. Dissertação (Mestrado em geografia Física) -FFLCH, Programa de Pós-Graduação em Geografia Física, USP, 1987.

BRANDÃO, R.S. As interações espaciais e o clima: incorporação das análises térmicas e energéticas no planejamento urbano. Tese (Doutorado em Tecnologia da Arquitetura), Programa de Pós-Graduação FAUUSP, São Paulo, 2009.

BURROUGH, P.A. Principles of Geographic Information Systems for Land Resource Assessment. Monographs on Soil and Resources Survey No. 12, Oxford Science Publications, New York, 1986.

C. REN, E. NG, L. KATZSCHNER. Urban climatic map studies: a review Int. J. Climatol., v.31, 2010. p. 2213-2233 http://dx.doi.org/10.1002/joc.2237

CABRAL, E. Análise das alterações climáticas da cidade de São Paulo (1887-1995) no contexto da expansão de sua mancha urbana. Dissertação (Mestrado em geografia Física), FFLCH, Programa de Pós-Graduação em Geografia Física, USP, 1996.

CARRERAS, C.; MARIN, M.; MARTINS, VIDE, J.M. MORENO, M.C.; SABI, J. Modificaciones térmicas em lãs ciudades. Avance sobre La islã de calor em Barcelona. Documents d'analisi geográfica, Barcelona, v.17, 1990. p. 51-77.

CHANGNON, S. A. A rare long record of deep soil temperatures defines temporal temperature changes and an urban heat island, Climatic Change, vol. 42, 1999. p. 531-538.

CHEVAL, S., DUMITRESCU, A.The July urban heat island of Bucharest as derived from Modis images", Theoretical and Applied Climatology, vol. 91, n.1-4, p. 1-9, 2008.

CHUNG, U., CHOI, C., YUN, J.I., Urbanization effect on the observed change in mean monthly temperatures between 1951-1980 and 1971-2000 in Korea, Climatic Change, vol. 66, 2004, p. $127-136$.

COLLISCHONN, E.; MATTOS, G.P. Classificação de ambientes termicamente homogêneos para estudos de clima na camada dossel urbano - metodologia e aplicação à cidade de Pelotas/RS. Revista Brasileira de Climatologia, n.9, 2011, p. $56-67$.

COSTA, A.; LABAKI, L. Metodologia de medição em pontos fixos: torres de celular como alternativa viável. In: ENCONTRO NACIONAL DE TECNOLOGIA NO AMBIENTE CONSTRUÍDO, 11, 2006, Florianópolis. Anais...Florianópolis: ANTAC, 2006, p.218-226.

DANNI, I. M. Aspectos Temporo-espaciais da Temperatura e Umidade relativa de Porto Alegre em Janeiro de 1982: contribuição ao estudo do clima urbano. São Pulo, 1987. 129p. Dissertação (Mestrado em Geografia Física) - Faculdade de Filosofia, Letras e Ciências Humanas, Universidade de São Paulo.

DANNI, I.M. A ilha térmica de Porto Alegre: contribuição ao estudo do clima urbano. Boletim Gaúcho de geografia, Porto alegre, n.5, 1980, p. 33-48. 
DESPLAT J, SALAGNAC J-L, KOUNKOU-ARNAUD R, LEMONSU A, COLOMBERT $M$, LAUFFENBURGER M, MASSON V. 2009. EPICEA Project [2008-2010], Multidisciplinary study of the impacts of climate change on the scale of Paris. In Paper Presented at the 7th International Conference on Urban Climate, Yokohama, Japan. 2009.

DREBS, A.; VADJA, A.; TUOMENVISTA, H. Air temperature gradient studies in Helsinki metropolitan area during 2002-2006. In: INTERNACIONAL CONFERENCE ON URBAN CLIMATE, 6, 2006, Göteborg. Preprints... Göteborg: IAUC, 2006. p. 736-738.

EM-DAT, The International Disaster Database, CRED, Disponível em: HTTP://www.emdat.be/. Acesso em: 01 jun. 2014

ERELL E, PORTNOV BA, ETZION Y. Mapping the potential for climate-conscious design of buildings. Building and Environment, V.38, 2003, p. 271-281.

EZBER, Y., SEN, O.L., KINDAP, T., KARACA, M. Climatic effects of urbanization in Istanbul: a statistical and modeling analysis, International Journal Climatology, vol. 27, 2007, p. 667679.

FIALHO, E.S. Análise temporoespacial do campo térmico na Ilha do governador-RJ em situações sazonais de verão e inverno. Dissertação (Mestrado em Geografia), Centro de Ciências matemáticas e da natureza-Instituto de Geociências da UFRJ, Rio de Janeiro, 2002.

GANHO, N. Insolação e Temperatura em Coimbra: Regimes médios e prováveis na estação meteorológica do IGU. Cadernos de Geografia, Coimbra, n.11, 1992, p. $55-85$.

GARCÍA, M.C. M. La Intensidad de la "Isla de Calor" de Barcelona. Comparación con otras Ciudades Españolas. Alísios Revista de Geografia, Barcelona, v.1, 1991, p. 47-53.

GARTLAND, L. Ilhas de calor: como mitigar zonas de calor em áreas urbanas. São Paulo: Oficina de textos, 2010.

GRIMMOND, C. S. B. Progress in measuring and observing the urban atmosphere, Theoretical and Applied Climatology, v. 84, 2006, p. 3-22.

GRIMMOND, C.S.B., OKE, T.R. An evapotranspiration-interception model for urban areas, Water Resources Research, v. 27, 1991, p. 1739-1755.

HAGE, K.D. Nocturnal temperatures in Edmonton, Alberta. Journal of Applied Meteorology, New York, v.11, n. 2, 1972, p. 123-129.

HEISLER, Gordon et al. Land-cover influences on air temperature in and near Baltimore, MD. In: INTERNACIONAL CONFERENCE ON URBAN CLIMATE, 6, 2006, Göteborg. Preprints...Göteborg: IAUC, 2006. p. 392-395.

HINKEL, K.M.; NELSON, F.E. KLENE, A.F.; BELL, J.H. The urban heat island in winter at Barrow. Alaska. International journal of climatology, Viena, v.23, n. 15, 2003, p. 18891905.

HOMAR, V., RAMIS, C., ROMERO, R., ALONSO, S. Recent trends in temperature and precipitation over the Balearic Islands (Spain). Climatic Change, vol. 98, 2010, p.199-211.

IMHOFF, M.L, ZHANG, P., WOLFE, R.E., BOUNOUA, L. Remote sensing of the urban heat island effect across biomes in the continental USA, Remote Sensing of Environment, vol. 114, pp. 504-513, 2010.

ACERO, J.A.; ARRIZABALAGA, J.; KUPSKI, S.; KATZSCHNER, L. Urban heat island in a coastal urban area in northern Spain Theor. Appl. Climatol. (2012). Disponível em: <http://dx.doi.org/10.1007/s00704-012-0774-z>. Acesso em: 20 jun. 2013. 
KANDA, M. Progress in the scale modeling of urban climate: Review. Theoretical Applied Climatology, vol. 84, 2006, p. 23-33.

KARAM, H.A., PEREIRA FILHO, A.J., MASSON, V., NOILHAN, J., MARQUES FILHO, E.P., Formulation of a tropical town energy budget, Theoretical Applied Climatology, vol. 101, 2010, p.109-120.

KATZSCHNER, L. e MÜLDER, J. Regional climatic mapping a tool for sustainable development, Journal of Environmental Management, Elsevier B.A. Amsterdam, V. 87/2, 2008, p. 262267.

KATZSCHNER, L., FREIRE, T., NERY, J., CARVALHO, L. Urban Climate Study of Salvador: Thermal Comfort Pattern In: ENCONTRO NACIONAL DE CONFORTO NO AMBIENTE CONSTRUÍDO II ENCONTRO LATINO AMERICANO DE CONFORTO NO AMBIENTE CONSTRUÍDO, 5, 1999, Fortaleza. Anais... Fortaleza: ANTAC, 1999.

KNOCH K. Die Landsklima-aufanhme, Wesen und Methodik. Berichte der Deutschen Wetterdienst, v.85, 1963, p.64,

KNOCH K. Uber das Wesen einer Landesklimaaufnahme. Meteorologische Zeitschrift. V. 5, 1951, p. 173.

KUSAKA, H., KONDO, H., KIKEGAWA, Y., KIMURA, F. A simple single-layer urban canopy model for atmospheric models: comparison with multi-layer and slab models, Boundary Layer Meteorology, vol. 101, 2001, p. 329-358.

LEMONSU, A., GRIMMOND, C. S. B., MASSON, V. Modeling the surface energy balance of the core of an old mediterranean city: Marseille, Journal Applied Meteorology, vol. 43, p. 312$327,2004$.

LIN, W., WANG, B., LI, J., WANG, X., ZENG, L., YANG, L., LIN, H. The impact of urbanization on the monthly averaged diurnal cycle in october 2004 in the Pearl river delta region, Atmósfera, vol. 23, n. 1 (Jan), 2010, p. 37-51.

LOMBARDO, M. Ilha de calor nas Metrópoles: o exemplo de São Paulo. São Paulo: Hucitec, 1985.

MAITELLI, G.T. Uma abordagem tridimensional de clima urbano em área tropical continental: o exemplo de Cuiabá-MT. Tese (Doutorado em geografia Física), FFLCH, Programa de Pós-Graduação em Geografia Física, 1994.

MAITELLI, G.T.; SOUZA, S.C.; PINHO, J.G. The magnitude of urban heat island in the tropical áreas Brazil. In: INTERNATIONAL CONFERENCE ON URBAN CLIMATE, 5, ICUC: Proceedings..., Lodz Poland, 2003.

MARTINS, L.A. A temperatura do ar em Juiz de Fora-MG: Influências do sítio e da estrutura urbana. Dissertação de Mestrado. Rio Claro-SP, 1996.

MASSON, V. A physically-based scheme for the urban energy budget in atmospheric models. Bound-Layer Meteorology, vol. 94, 2000, p. 357-397.

MELHUISH, E.; PEDDER, M. Observaing na urban heat island by bicycle. Weather, London, v.53, n. 4, 1998, p. 121-128.

MENDONÇA, F.A. Clima e planejamento urbano em Londrina - proposição metodológica e de intervenção urbana a partir do estudo do campo térmico. In: MENDONÇA, F.; MONTEIRO, C.A.F. (Orgs.) Clima Urbano. São Paulo: Contexto, 2003. 
MENDONÇA, F.A. O clima urbano de cidades de porte médio e pequeno: aspectos teóricometodológicos e estudos de caso. In: SANT'ANNA NETO, J.A.; ZAVATINI, J.A. (Orgs), Variabilidade e mudanças climáticas: Implicações ambientais e sócioeconômicas. Maringá: UEM, p.167-192, 2001.

MENDONÇA, R.S.R.; ASSIS, E.S. Conforto térmico urbano: estudo de caso do bairro floresta em Belo Horizonte, Minas Gerais. Ambiente Construído, v.03, n.03, 2003, p. 3977-3986.

MOCHIDA A, SASAKI K, LUN I, OBA H. Management, control and design of urban climate based on the heat balance analysis of outdoor space. In Paper Presented at the ISWE School, Tokyo, Japan, 2007

MONTEIRO, A. A cidade um espaço de (dês)encontros entre a evolução do conhecimento e a qualidade de vida dos seres humanos. Mercartor, v.9, n. espacial 1, 2010. p. $7-23$.

MONTEIRO, A. O clima urbano de Porto: contribuição para a definição das estratégias de planejamento e ordenamento do território. Fundaçao Calouste Gulbenkian-Junta Nacional de Investigação Científica e Tecnológica: Lisboa, 1997.

MONTEIRO, A. Riscos climáticos: hazards, áleas, episódios extremos. In: AMORIM, M.C.C.T.; SANT'ANNA NETO, J.L.; MONTEIRO, A. (Orgs). Climatologia Urbana e regional: questões teóricas e estudos de caso. São Paulo: Outras Expressões, 2013.

MONTEIRO, C. A. F. A cidade como processo derivador ambiental e estrutura geradora de um "clima urbano". GEOSUL, Florianópolis, v.5, n.9. p. 80-114, 1990.

MONTEIRO, C. A.F. Adentrar a cidade para tomar-lhe a temperatura. GEOSUL. Florianópolis, v.5, n.9, p.61-79, 1990.

MONTEIRO, C. A.F. Por um suporte teórico e prático para estimular estudos geográficos do clima urbano no Brasil. GEOSUL, Florianópolis, v.5, n.9, p. 7-19, 1990.

MONTEIRO, C.A.F. \& MENDONÇA, F. (Org.) Clima Urbano. São Paulo: Editora Contexto, 2003.

MONTEIRO, C.A.F. Adentrar a cidade para tomar-lhe a temperatura. Geosul, ano V, n.9. Editora UFSC, 1990.

MONTEIRO, C.A.F. Teoria e Clima Urbano. São Paulo: IGEO/USP, 1976.

MURPHY, D.J., HALL, M.H., HALL, C.A.S., HEISLER, G.M., STEHMAN, S.V., ANSELMIMOLINA, C., 2011, The relationship between land cover and the urban heat island in north e Astern Puerto Rico, International Journal Climatology, vol. 31, n. 8 (June), 2001, p. 1222-1239.

NERY J, FREIRE T, ANDRADE T, KATZSCHNER L. Thermal comfort studies in humid tropical city. In Paper Presented at the 6th International Conference on Urban Climate, Göteborg, Sweden, 2006.

NG E, KATZSCHNER L, WANG Y, REN C, CHEN L. Working Paper No. 1A: draft urban climatic analysis map-urban climatic map and standards for wind environment-feasibility study. Technical Report for Planning Department HKSAR. Report No. WP1A. Planning Department of Hong Kong Government: Hong Kong. 2008.

OKE, T. R. Boundary Layer Climates. London: Methuem \&Ltd. A. Halsted Press Book, John Wiley \&Sons, New York, 1978, 372p.

OKE, T. R. Canyon geometry and the nocturnal urban heat island: comparison of scale model and field observation, Journal of Climatology, vol. 1, 1981. p. 237-254. 
OKE, T. R. Initial Guidance to obtain representative meteorological observations at urban sites. World Meteorological Organization, Geneva, 2004.

OKE, T. R. Towards better scientific communication in urban climate, Theoretical and Applied Climatology, vol. 84, 2006, p. 179-190.

OKE, T.R. The distinction between canopy and boundary -layer heat islands. Atmosphere, v. 14,1976 , p. 268-277.

OKE, T.R. The energetic basis of the urban heat island. Quarterly Journal of the Royal Meteorological Society, v.108, n.455, jan. 1982, p.1-24.

$\mathrm{OKE}, \mathrm{T}$. R. The technical conference on urban climatology and its applications with special regard to tropical areas. México, 1984, proceedings. Genova, World Meteorological Organization (WMO, no. 652), 1986.

OKE, T.R. The urban energy balance. Progress in Physical Geography, n.12, 1988, p. 471508.

OLIVEIRA, C.S.; OLIVEIRA, D.E.; ASSIS, D.C. e FERREIRA, C.C.M. Diferenças térmicas ocasionadas pela alteração da paisagem natural em uma cidade de porte médio Juiz de ForaMG. Artigo disponível em: WWW.ufjf.br/labcaa/files/2008/08/Diferenas.pdf>. Acesso em: 28 out. 2012.

PAULEIT, S.; ENNOS, R.; GOLDING, Y. Modeling the environmental impacts of urban land use and land cover change a study in Merseyside, UK. Landscape and Urban Planning, Amsterdã, n.71, p. $295-310,2005$.

PEZZUTO, C. C.; LABAKI, L. C.; FRANCISCO FILHO, L. Distribuição horizontal da temperatura do ar em uma região central na cidade de campinas, SP In: ENCONTRO NACIONAL DE CONFORTO NO AMBIENTE CONSTRUÍDO, 7, 2005, Maceió. Anais... Maceió: UFAL - ANTAC, 2005. p.1499-1506.।

POLIZEL, J.L. Geotecnologias e clima urbano: aplicação dos recursos de sensoriamento remoto e sistemas de informações geográficas na cidade de Piracicaba, SP. Tese (Doutorado em geografia Física)- Programa de Pós-Graduação em Geografia Física, São Paulo, 2009.

REN C, NG E, KATZSCHNER L. An investigation into developing an urban climatic map for high density living-initial study in Hong Kong. In Paper Presented at the 2nd PALENC, Greece, 2007.

REN, C., YAN-YUNG NG, E., KATZSCHNER, L., Urban climatic map studies: a review, International Journal of Climatology, vol. 31, n. 15 (Dez), 2010, p. 2213-2233.

RIBEIRO, C.A.M.; CARVALHO, H.J.M.; SANTOS, M.A. Metodologia para análise do sombreamento em centros urbanos. In: III Simpósio Brasileiro de Ciências Geodésicas e Tecnologias da Informação, Recife-PE, 2010, p. 1-9.

SOLECKI, W. D.; ROSENZWEIG, C.; PARSHALL, L.; POPE, G.; CLARK, M.; COX, J.; WIENCKE, $M$. Mitigation of the heat island effect in urban New Jersey. Environmental Hazards, Amsterdã, n.6, p. $39-49,2005$.

SOUZA, L.C.L. Determinação e apresentação do fator de visão do céu através de um SIG 3 D. Bauru. Livre Docência - Faculdade de arquitetura, artes e comunicação da Universidade de São Paulo, 2003. 
STATHOPOULOU, M., CARTALIS, C. Downscaling AVHRR land surface temperatures for improved surface urban heat island intensity estimation, Remote Sensing of Environment, vol. 113, 2009, p. 2592-2605.

STEWART, I.; OKE, T. Classifyns urban climate Field sites by "Local climate zones": the case of Nagano, Japan. In: The seventh International Conference an Urban Climate. Japan, 2009.

STREUTKER, D.R. Satellite-measured growth of the urban heat island of Houston, Texas, Remote Sensing of Environment, vol. 85, 2003, p.282-289.

SUN, C.Y., BRAZEL, A.J., CHOW, W.T.L., HEDQUIST, B.C., PRASHAD, L. Desert heat island study in winter by mobile transect and remote sensing techniques. Theoretical and Applied Climatology, vol. 98, 2009, p.323-333.

SVENSSON MK, THORSSON S, LINDQVIST S. A geographical information system model for creating bioclimatic maps-examples from a high, mid-latitude city. International Journal of Biometeorology, v.47, 2003, p.102-112.

TANAKA T, OGASAWARA T, KOSHI H, YOSHIDA S, SADOHARA S, MORIYAMA M. Urban environmental climate maps for supporting urban-planning related work of local governments in Japan: case studies of Yokohama and Sakai. In Paper Presented at the 7th International Conference on Urban Climate, Yokohama, Japan, 2009.

TARIFA, J.R. Análise comparativa da temperatura e umidade na área urbana e rural de São José dos Campos (SP). Geografia, Rio Claro-SP, v.2, n. 4, 1977, p. 59-80.

TSO, C. P. et al. An improvement to energy balance model for urban thermal environment analysis. Energy and Buildings, no. 14, 1990, p. 143-152.

TURKES, M., SUMER, U.M., DEMIR, I.L. Re-evaluation of trends and changes in mean, maximum and minimum temperatures of Turkey for the period 1929-1999, International Journal Climatology, vol. 22, 2002, p. 947-977.

USTRNUL Z, CZEKIERDA D. Application of GIS for the development of climatological air temperature maps: an example from Poland. Meteorological Applications, v. 12, 2005, p. 43-50.

VAN WEVERBERG, K., DE RIDDER, K., VAN ROMPAEY, A. Modeling the contribution of the Brussels heat island to a long temperature time series, Journal of applied meteorology and climatology, vol. 47, 2007, p. 976-990.

VENTURA, F.; ROSSI PIAL, P.; ARDIZZONI, E. Temperature and precipitation trends in Bologna (Italy) from 1952 to 1999. Atmospheric Research, London, v. 61, n.1, 2002, p. 203-214.

VIANNA, S.S.M. Caracterização do clima urbano em Teodoro Sampaio/SP. Dissertação (Mestrado em Geografia), Faculdade de Ciências e Tecnologia. Programa de Pós-Graduação em Geografia, UNESP-PP, 2006.

WANG G. Urban Climate, Environment and Urban Planning. Beijing Press: Beijing, China, (in Chinese), 2004.

XAVIER DA SILVA, J.; PERSSON, V.G.;LORINI, M.L.; BERGAMO, R.B.A.; RIBEIRO, M.F.; COSTA, A.J.S.T.; IERVOLINO, P.; ABDO, O.E. Índices de geodiversidade: aplicações de SGI em estudos de biodiversidade. In: GARAY, I e BRAULIO, D. Conservação da biodiversidade em ecossistemas tropicais. Petrópolis: Vozes, 2001.

XAVIER, T.M.B.S., PEREIRA FILHO, A.J., Análise das medições e observações meteorológicoclimáticas de superfície. In: Pereira Filho, A.J., Santos, P.M., Xavier, T.M.B.S. (eds), Evolução 
do tempo e do clima na região metropolitana de São Paulo, capítulo 6, Linear B; IAG/USP, 2007.

YOSHIKADO, $\mathrm{H}$. Interaction of the sea breeze with urban heat islands of different sizes and locations, Journal Meteorology Societal of Japan, vol. 72, 1994, p.139-143.

ZHANG, N., GAO, Z., WANG, X., CHEN, Y. Modeling the impact of urbanization on the local and regional climate in Yangtze River Delta, China, Theoretical and Applied climatology, vol.102, 2010, p.331-342. 